REFLEXIONES CONSTITUCIONALES SOBRE EL REASENTAMIENTO DE REFUGIADOS: EL RÉGIMEN JURÍDICO DEL REASENTAMIENTO EN CANADÁ Y EN ESPAÑA A LA LUZ DE LA NUEVA LEY DE ASILO Y DE LA PROTECCIÓN SUBSIDIARIA

ROSARIO GARCÍA MAHAMUT 
SUMARIO

1. INTRODUCCIÓN. 2. EL REASENTAMIENTO DE LOS REFUGIADOS: PRECISIONES CONCEPTUALES. 3. EL RÉGIMEN JURÍDICO DEL REASENTAMIENTO DE REFUGIADOS Y DE LAS PERSONAS QUE SE ENCUENTRAN EN SIMILARES CIRCUNSTANCIAS EN CANADÁ. 3.1. Consideraciones preliminares. 3.2. Características básicas del actual régimen jurídico del derecho de asilo en Canadá. 3.3. Condiciones, requisitos y financiación de los Programas de Reasentamiento: 3.3.1. Personas que pueden ser objeto de Reasentamiento y los requisitos que deben reunir para poder ser reasentadas. 3.3.2. La financiación (pública, privada o conjunta) como elemento basilar de los programas de Reasentamiento en Canadá. 3.3.3. Aspectos básicos de la tramitación y sustanciación del procedimiento para proceder al reasentamiento. 3.3.4. Algunas consideraciones sobre las políticas de reasentamiento en el sistema canadiense. 4. CUESTIONES JURÍDICAS BÁSICAS QUE PLANTEA EL REASENTAMIENTO DE REFUGIADOS EN ESPAÑA A LA LUZ DE LA NUEVA LEY DE ASILO Y DE LA PROTECCIÓN SUBSIDIARIA. 4.1. La disposición adicional primera y el desarrollo reglamentario. ¿Quiénes pueden ser reasentados en España? 4.2. Las causas de exclusión como motivos para denegar la posibilidad de reasentamiento. 4.3. Algunas reflexiones sobre la tramitación del procedimiento para reasentar a los refugiados en España. Especial referencia al papel del ACNUR. 4.4. Breves consideraciones sobre el estatuto de las personas reasentadas en España. 4.5. Los programas de reasentamientos en la UE y su incidencia en el ordenamiento interno. 5. ALGUNAS REFLEXIONES Y CONSIDERACIONES SOBRE EL USO ESTRATÉGICO DEL REASENTAMIENTO. 6. REFLEXIONES FINALES PARA EL ORDENAMIENTO ESPAÑOL. 


\title{
REFLEXIONES CONSTITUCIONALES SOBRE EL REASENTAMIENTO DE REFUGIADOS: EL RÉGIMEN JURÍDICO DEL REASENTAMIENTO EN CANADÁ Y EN ESPAÑA A LA LUZ DE LA NUEVA LEY DE ASILO Y DE LA PROTECCIÓN SUBSIDIARIA ${ }^{1}$
}

\author{
POR \\ ROSARIO GARCÍA MAHAMUT \\ Catedrática de Derecho Constitucional. Universidad Jaume I
}

\section{INTRODUCCIÓN}

El 20 de noviembre de 2009 entraba en vigor en España la Ley 12/2009, de 30 de octubre, reguladora del derecho de asilo y de la protección subsidiaria ${ }^{2}$ (en

${ }^{1}$ Este artículo es fruto del trabajo de investigación llevado a cabo en el Centre de Recherche en Droit Public de la Universidad de Montreal durante el mes de agosto de 2009, gracias a la Beca de Investigación de Estudios Canadienses que me fue concedida por el Ministerio de Asuntos Exteriores de Canadá. Al Director del Centre de Recherche en Droit Public, el Profesor Karim Benyekhlef, quisiera agradecer muy sinceramente desde estas páginas el apoyo intelectual y logístico prestado durante mi estancia. Agradecimiento que extiendo a su magnífico equipo de colaboradores.

2 Para un análisis en profundidad sobre la nueva regulación remitimos a GARCÍA MAHAMUT, R.: «El nuevo régimen jurídico del derecho de asilo y de la protección subsidiaria en España a la luz de la Ley 12/2009, de 30 de octubre: principales novedades y desafíos», en GARCÍA MAHAMUT, R. y GAPALASORO, J., La Ley 12/2009, de 30 de octubre, reguladora del derecho de asilo y de la protección subsidiaria, CEPC, Madrid, 2010, (próxima publicación). 
adelante LAPS). La nueva ley incorpora entre sus múltiples novedades, una habilitación expresa para que el Gobierno de la Nación pueda llevar a cabo programas de reasentamiento de refugiados en nuestro país.

$\mathrm{El}$ reasentamiento, precisemos, es un instrumento a través de cual un Estado selecciona, traslada y acoge en su país a refugiados que no pueden permanecer en un país de primer asilo por razones de seguridad (extensión transfronteriza de un conflicto al país de primera acogida, presencia de elementos del país perseguidor en el país de primera acogida, etc.) o de inexistencia de unas condiciones mínimas de subsistencia (enfermedades que no pueden ser atendidas en el país de primera acogida, crisis de refugiados de larga duración que agotan las capacidades del país de primera acogida, etc.) y les protege con un estatuto estable de residencia. Desde esta perspectiva, el reasentamiento no sólo es un mecanismo de protección de los refugiados sino también una solución duradera para aquellos refugiados que ni pueden regresar a su país de origen ni permanecer en el país tercero con garantías de seguridad.

La Disposición adicional primera de la nueva LAPS dispone textualmente lo siguiente: «El marco de protección previsto en la presente Ley será de aplicación a las personas acogidas en España en virtud de Programas de Reasentamiento elaborados por el Gobierno de la Nación, en colaboración con el Alto Comisionado de las Naciones Unidas para los Refugiados, y, en su caso, otras Organizaciones Internacionales relevantes. El Consejo de Ministros, a propuesta de los Ministros de Interior y de Trabajo e Inmigración, oída la Comisión Interministerial de Asilo y Refugio, acordará anualmente el número de personas que podrá ser objeto de Reasentamiento en España en virtud de estos programas. Los refugiados reasentados en España tendrán el mismo estatuto que los refugiados reconocidos en virtud de las disposiciones de la presente ley».

Tal previsión constituye una magnífica expresión de que nuestro país avanza decididamente por la senda del compromiso en la protección de los refugiados más allá de las exigencias derivadas de su condición de Estado parte firmante de la Convención de Ginebra de $1951^{3}$. Efectivamente, cabe recordar que los programas de reasentamiento no son sustitutivos de, ni incompatibles con, los sistemas individuales de asilo. Se trata de políticas complementarias que dan respuestas a distintas necesidades. Los sistemas nacionales de determinación del estatuto de refugiado de las personas que solicitan tal protección constituyen el

${ }^{3}$ Porque, como señala el ACNUR, «Ningún país está legalmente obligado a reasentar a refugiados. Sólo un pequeño número de Estados lo hace de manera regular, destinando presupuestos, diseñando programas y ofreciendo cuotas anuales de reasentamiento» (Manual de Reasentamiento del ACNUR, Ginebra, 2004. p. 3. Fuente: http://www.acnur.org/t3/que-hace/reasentamiento/). 
mecanismo a través del cual los Estados atienden sus obligaciones internacionales otorgando protección internacional a aquellas personas que llegan a su territorio demandando esa protección. Las políticas de reasentamiento, por su parte, constituyen una manifestación voluntaria de solidaridad de los Estados frente a los refugiados y frente a los países de primera acogida.

Pero no sólo, con tal previsión España se suma a la consecución de uno de los retos que forman parte del Sistema Europeo Común de Asilo (SECA $)^{4}$ y que destaca el reasentamiento como una parte importante de la dimensión exterior de la política de asilo de la Unión Europea, entendida ésta como instrumento que contribuye a resolver situaciones prolongadas y difíciles o para dar respuesta a situaciones de emergencia humanitaria ${ }^{5}$.

Con independencia de que la política comunitaria logré imponer a los Estados Miembros la adopción de programas de reasentamiento de refugiados

${ }^{4}$ Qué duda cabe que en la Unión Europea se ha pasado de la consideración del derecho de asilo como un derecho de soberanía nacional a una construcción supranacional que tiene por objetivo hacer de la Unión Europea un espacio único de protección donde ésta alcance las máximas cotas. Desde esta perspectiva, el asilo constituye un instrumento esencial para la construcción de una auténtica Unión Política, en la medida en que integra el Espacio de Libertad, Seguridad y Justicia, junto con la inmigración, la política de visados y la gestión de las fronteras. El asilo se percibe, pues, como una herramienta más, singularizada pero igual de funcional, para lograr que la UE sea un Espacio de convivencia pacífica, regido por los valores de la Libertad, la Seguridad y la Justicia. Sin género de dudas, ello adquiere un especial significado el marco del Tratado de Lisboa en el que la casi plena europeización del espacio de libertad, seguridad y justicia cobra un nuevo significado en la medida en que el Tratado define un nuevo marco jurídico que en modo alguno cabe soslayar.

5 Bajo el compromiso del Programa de la Haya de construcción de un Sistema Europeo Común de Asilo, la Comisión lanzó el Libro Verde sobre el futuro Sistema Europeo Común de Asilo. En él se venía a destacar la importancia del reasentamiento como una parte importante de la dimensión exterior de la política de asilo de la Unión Europea y venía a incentivar a los Estados miembros a avanzar en este ámbito. A partir de la contribuciones realizadas al Libro Verde, la Comisión, en junio de 2008, elaboró un Plan de Acción de Asilo entre cuyos compromisos figura el de presentar un esquema de reasentamiento comunitario. En octubre de 2008 el Consejo Europeo aprobó el Pacto Europeo sobre Migración y Asilo en cuyo Capítulo IV ("Construir una Europa del Asilo»), entre otras, se insta a poner en marcha la posibilidad del reasentamiento de refugiados por parte de los Estados miembro además de la recolocación intracomunitaria en situaciones de crisis. A día de hoy, con el Tratado de Lisboa en vigor, con la Agencia Europea del Asilo a punto de entrar en funcionamiento y la aprobación del Programa de Estocolmo la dimensión exterior del asilo cobra un especial significado, especialmente a partir de la propuesta que, en septiembre de 2009, realizó la Comisión de creación de un «Programa conjunto de la UE en materia de reasentamiento». Este programa se propone convertir el reasentamiento dentro de la UE en un instrumento más eficaz para proteger a los refugiados, consiguiendo una cooperación más estrecha y práctica entre los Estados miembros de la UE. 
en el marco comunitario, lo cierto es que España avanza claramente en su voluntad de comprometerse en la protección de los refugiados más allá de las exigencias derivadas de su condición de Estado parte firmante de la Convención de Ginebra de 1951. Buena prueba de ello es que fruto de lo dispuesto en la Disposición adicional primera de la nueva Ley, el Consejo de Ministros en su reunión de 29 de enero de 2010 ha aprobado el primer programa de reasentamiento para acoger a 75 refugiados en el presente año. España se suma así al conjunto reducido de países ${ }^{6}$ que cuentan con Programas de reasentamiento de refugiados como expresión de compromiso y de solidaridad internacional, entre los que cabe destacar Canadá por su consolidada experiencia e importante volumen de refugiados reasentados en su territorio.

El alto número de refugiados que ha reasentado Canadá en 2009, cuya cifra asciende a casi 11.000 refugiados (el cupo para refugiados reasentados con subvención del gobierno ha sido de entre 7.300 y 7.500, mientras que los reasentados con financiación privada ha sido de entre 3.300 y 4.500), constituye el mejor de los testimonios de solidaridad de un país cuyo Gobierno invirtió de forma adicional en $2006, .4$ mil millones de dólares para cinco años en programas de reasentamiento.

La experiencia acumulada por Canadá a través de los Programas de Reasentamiento Humanitario y de Refugiado, que permite ofrecer soluciones a situaciones de emergencia y prolongadas de refugio a través de un sofisticado sistema de ayudas y servicios básicos para los refugiados reasentados que se dispensan a través de una red de servicios de reasentamiento y programas obligatorios federales y provinciales; así como su sistema de garantías, hace susceptible de estudio una experiencia que tras distintas reformas y una evolución constante en el derecho humanitario parte desde la Segunda Guerra Mundial.

España, por su parte, con una baja tasa de solicitudes de asilo (4.517 en $2008)^{7}$ y de concesión de estatutos de refugiados (151 en 2008) y de protección subsidiaria o humanitaria (126 en 2008), ha practicado reasentamientos ad hoc, para casos concretos solicitados por el $\mathrm{ACNUR}^{8}$, conforme a la derogada ley de asilo9. Sin embargo, va a necesitar articular futuros programas de reasenta-

${ }^{6}$ En la UE, actualmente, son once los países que practican Programas de reasentamiento, incluida España.

${ }^{7}$ Véase la Memoria de la Oficina de Asilo y Refugio de 2008.

8 Sobre los distintos instrumentos, decisiones, manuales, etc., utilizados por el ACNUR y a los que remitimos pueden consultarse en http://www.acnur.org/t3/que-hace/reasentamiento/.

9 Tienen razón aquellos que apuntaban que a España no se le podía considerar país de reasentamiento al no contar con Programas de Reasentamiento, a pesar de haber reasentado ad hoc a aquellos refugiados que le solicitaba el ACNUR en momentos puntuales. 
miento que aporten el bagaje y experiencias de Estados como el de Canadá, descentralizado políticamente, que cuenta con una amplia experiencia sobre la materia. De ahí, el interés de la investigación que tiene por objeto, entre otros, profundizar en la dimensión constitucional interna de los derechos de los refugiados en Canadá. Dimensión que va más allá de la mera expresión de la voluntad del Estado en su compromiso de solidaridad internacional.

Dar a conocer en España, a través de un estudio riguroso, las políticas públicas que en materia de reasentamiento de refugiados se llevan a cabo en otros países, en este caso Canadá, permite poner en valor un dato de la máxima relevancia en el funcionamiento de los sistemas nacionales de asilo, tal y como en ocasiones ha apuntado el ACNUR: Las operaciones de reasentamiento dinamizan las estructuras de acogida, tanto material como legal, de los solicitantes de asilo y de los refugiados. La experiencia de países que practican reasentamientos indica que los procesos de selección e integración de los reasentados tienen efectos positivos en todas las instituciones implicadas, especialmente para países como España que trabajan con un considerable volumen de solicitantes de asilo sin auténticas necesidades de protección.

Sin género de dudas, articular programas efectivos y eficaces de reasentamiento en España nos coloca con carácter previo ante decisiones de políticas públicas de calado y ante numerosas cuestiones técnico-jurídicas de no menor entidad que exigen respuestas normativas con carácter previo al diseño de las políticas públicas. A ningún jurista escapan los retos que se presentan en nuestro Estado Autonómico a la hora de articular los distintos recursos que se ponen a disposición de las CCAA que se hacen cargo de la integración de los refugiados en nuestro país. Ello implica reflexionar sobre algunas de las cuestiones que se plantean con el cupo de refugiados que decide el Gobierno pero cuyos gastos asumirán en buena medida las CCAA.

Aportar, en consecuencia, algunas experiencias de un sistema consolidado como el canadiense así como conocer las respuestas jurídicas a algunas de las cuestiones más espinosas en nuestro ámbito interno constituyen objeto del presente trabajo de investigación.

\section{EL REASENTAMIENTO DE LOS REFUGIADOS: PRECISIONES CONCEPTUALES}

Antes de proseguir con nuestro estudio conviene dar respuesta clara a estas dos cuestiones básicas: ¿qué se entiende por reasentamiento de refugiados? y ¡en qué consiste el reasentamiento de refugiados? 
El reasentamiento implica, como ya se ha dicho, la selección y el traslado de refugiados desde un primer país de asilo en el que el refugiado ha buscado protección a un tercer país que ha aceptado admitirles como refugiados y a protegerles con un estatuto estable de residencia.

El reasentamiento de refugiados, tal y como lo define el ACNUR, constituye un mecanismo para la protección de los refugiados, una solución duradera y un instrumento de solidaridad internacional. Ahora bien, conviene adelantar y precisar, tal y como lo hace el ACNUR que «El reasentamiento a un tercer país es una posibilidad de carácter excepcional a la que se recurre únicamente en algunos casos muy específicos que cumplen con criterios determinados» ${ }^{10}$.

Efectivamente, el reasentamiento bajo los auspicios del ACNUR está orientado principalmente, tal y como textualmente se recoge en el Manual de Procedimiento, «a resolver las necesidades esenciales de los refugiados cuya vida, libertad, seguridad, salud y otros derechos fundamentales se encuentran en riesgo en el país donde han buscado protección. También está considerado como una solución duradera para los refugiados que, aunque no tienen una necesidad de protección inmediata, sí tienen imperiosas razones para ser trasladados de su país de asilo». Es más, debe incidirse en la idea, tal y como lo hace el ACNUR, de que "La decisión de reasentar a un refugiado normalmente sólo se toma en ausencia de otras opciones tales como la repatriación voluntaria y la integración local, o cuando, bajo un enfoque integral de las soluciones duraderas, el reasentamiento se presenta como la solución óptima para un individuo o grupos de refugiados». En consecuencia, no cabe perder de vista que el reasentamiento se considera el último recurso para el refugiado que no puede ni regresar a su país de origen ni permanecer en el país tercero con garantías de seguridad. Tampoco cabe olvidar que estos refugiados son precisamente los más vulnerables (niños, mujeres solas con hijos, personas traumatizadas o gravemente enfermas).

El reasentamiento es una solución duradera, al igual que la repatriación voluntaria ${ }^{11}$ y la integración local ${ }^{12}$, que debe considerarse cuando los refugiados

10 «Información sobre el Reasentamiento» (ACNUR). Fuente: http://www.acnur.org.

${ }^{11}$ Cuando prevalecen condiciones en las cuales se puede volver con seguridad y dignidad, el regreso a casa se considera como la solución más beneficiosa para los refugiados ya que posibilita que continúen su vida en un entorno con el que están familiarizados, de ahí que, desde la perspectiva del ACNUR, «La parte medular de la repatriación voluntaria es el regreso «en condiciones de seguridad y dignidad», es decir, el regreso en condiciones de seguridad física, legal y material , siendo el producto final la restauración completa de la protección nacional» (Manual de Reasentamiento... op. cit., Cap. 2, p. 4). Conviene destacar que el Manual de Reasentamiento del ACNUR, fue aprobado por el Comité Ejecutivo del ACNUR en 1996. Se utiliza la edición de 2004 y el Manual contiene: los criterios de reasentamiento del ACNUR, las consideraciones re- 
no puedan repatriarse y estén en peligro en su país de asilo: «la decisión de optar por el reasentamiento se toma a la luz de las perspectivas que existan de encontrar otras soluciones duraderas y cuando no haya alternativa posible ni duradera de eliminar el peligro que exista para la integridad física y la condición legal de la persona» ${ }^{13}$.

El reasentamiento, sin lugar a duda, constituye una clara expresión de solidaridad internacional y un eficaz mecanismo ${ }^{14}$ de distribución de responsabilidad entre los Estados, dado que ello, como señala el ACNUR, permite compartir de manera equitativa la carga entre Estados y reducir los problemas que afectan al país de primer asilo ${ }^{15}$. Ello en lógica coherencia con el reconocimiento de que «el respeto de los Estados a sus responsabilidades de protección internacional hacia los refugiados se fortalece mediante la solidaridad internacional y que el régimen de protección a los refugiados se fortalece con el compromiso de cooperación internacional en un espíritu de responsabilidad y de compartir efectivamente la carga entre todos los Estados» ${ }^{16}$. Como nos recuerda el ACNUR, algunos de los pa-

levantes para la identificación de refugiados en necesidad de reasentamiento y capítulos de países que incluyen la selección de refugiados y modelos de tramitación, gestión de los servicios de recepción y asentamiento que se otorgan por parte de los países de reasentamiento. El Capítulo de país se actualiza regularmente por las autoridades nacionales competentes A efectos del Reasentamiento conviene también tener presente el documento del ACNUR «Modulo Autoformativo: Programa de Aprendizaje de Reasentamiento» (octubre de 2009).

${ }_{12}$ La integración local de los refugiados en su primer país de asilo es una de las soluciones duraderas, especialmente cuando no se vislumbra la posibilidad de una repatriación voluntaria. La integración local es consecuencia de la concesión formal del estatuto de refugiado y de asistencia para que el refugiado pueda vivir de forma independiente en la comunidad.

13 Manual de Reasentamiento... op. cit., Cap. 2, p. 1. Debe recordarse que a comienzos de los años 80 el reasentamiento comenzó a considerarse por el ACNUR como la última solución duradera deseable. Efectivamente, la preocupación de que el reasentamiento a gran escala estuviese llevando al abandono del asilo político en los primeros países de asilo y sirviera como factor de atracción para que las personas abandonaran su hogar por motivos sociales y económicos, junto con un mayor énfasis en la repatriación voluntaria tras el final de la Guerra Fría, vinieron a limitar el entusiasmo por el reasentamiento (Ver sobre el particular TROELLER, Gary: «UNHCR Resettlement: Evolution and Future Direction», Refugee Law, núm. 85, 2002, p. 88.

${ }^{14}$ Quizás convenga obviar el calificativo de eficaz en la medida en que son pocos los países del mundo los que practican el reasentamiento.

15 Aunque, para algunos, el resurgimiento del discurso sobre el reasentamiento se ha de aplaudir, «el problema con la actual configuración tripartita del ACNUR es que existe el riesgo de que contagie al reasentamiento su propia y esquizofrénica crisis de identidad sin saber cómo actualizar su función de manera efectiva» (LABMAN, Shauna: «Resettlement's renaissance: a cautionary advocacy», Refuge, n. 24 (vol. 2), 2007, p. 36).

16 Preámbulo, punto 8, Declaración de los Estados Parte de la Convención de Ginebra de 1951 y/o su Protocolo de 1967 (diciembre 2001). 
íses más pobres del mundo están soportando una parte desproporcionada de la carga, con refugiados que buscan a menudo asilo en los países vecinos, muchos de los cuales tienen un bajo nivel de desarrollo económico. Como destacan las estadísticas del ACNUR, la inmensa mayoría de los refugiados huyen a los países vecinos y permanecen dentro de lo que se considera su región de origen, «la mayoría de las regiones generadoras de refugiados asilan en promedio entre el 83\% y el $90 \%$ de sus "propios» refugiados. El ACNUR estima que 1.6 millones de refugiados —el 14\% del total de refugiados en el mundo - viven fuera de sus regiones de origen ${ }^{17}$. De hecho, se calcula que solamente en 2010 , de los aproximadamente diez millones de refugiados de todo el mundo, 203.000 refugiados necesitarán ser reasentados ${ }^{18}$. En 2008, países de todo el mundo ofrecieron reasentamiento a unos 65000 refugiados. De ellos, 4378 refugiados, o sea el $6,7 \%$, fueron reasentados en alguno de los países de la UE.

En fin, la integración constituye uno de los elementos de gran envergadura al que los países deberán prestar una especial atención. Comparto la apreciación de quienes defienden que la integración es un elemento fundamental para el éxito del reasentamiento de los refugiados. Ello, sin embargo, implica, como tendremos ocasión de comprobar, que Programas de Reasentamiento pongan un especial énfasis en la potencial integración como criterio para determinar si un refugiado puede ser apto o no para el reasentamiento.

\section{EL RÉGIMEN JURÍDICO DEL REASENTAMIENTO DE REFUGIADOS Y DE LAS PERSONAS QUE SE ENCUENTRAN EN SIMILARES CIRCUNSTANCIAS EN CANADÁ}

\subsection{Consideraciones preliminares sobre el sistema de protección de los Refugiados}

Canadá es un país que tradicionalmente ha respondido con generosidad a las crisis de refugiados y a las emergencias humanitarias. Es uno de los pocos países del mundo que se ha comprometido con serios programas de reasentamiento de refugiados. Tras EEUU, es el segundo país del mundo en números de refugiados reasentados. Cuenta con una larga tradición en los Programas de Reasentamiento y

17 «El Reasentamiento Solidario en el 2008: Avances y nuevos desafios» (ACNUR- Protegiendo a los Refugiados, http://www.acnur.org/paginas/index.php?id-pag=8040).

${ }_{18}$ De una cifra en la que el ACNUR estima que 747.000 refugiados en todo el mundo estarán en necesidad de reasentamiento en los próximos años en base a las evaluaciones de necesidades anuales. 
cabe destacar que, desde la Segunda Guerra mundial hasta el 2008, Canadá ha reasentado a más de 860.000 refugiados y personas en circunstancias similares ${ }^{19}$.

En relación con el perfil de los solicitantes de asilo en Canadá ${ }^{20}$ debe destacarse que, si a principios de los años 90 Sri Lanka, Somalia e Irán fueron los principales países de procedencia de los solicitantes de asilo en Canadá, a finales de los 90 hasta el 2001 a Sri Lanka se suman China, Pakistán y Hungría. De 2001 a 2007 los principales países de procedencia de solicitantes fueron Pakistán, Colombia y Méjico. Durante 2007, los principales países de procedencia de los solicitantes de asilo fueron Méjico, Haití, Colombia y China ${ }^{21}$.

Como ha ocurrido en cierto modo con Europa, en Canadá el número de solicitantes de asilo ha oscilado considerablemente. Si en 1988 la cifra de solicitantes alcanzó su máximo nivel con 45.000 solicitudes, esta cifra se redujo a algo menos de la mitad (20.000) al año siguiente (1989). En 2001 se volvió a alcanzar la cifra de 44.000 solicitudes disminuyendo a 20.000 solicitudes en 2005. En el 2008 la cifra ascendió a casi 37.000 solicitudes.

Dado que en estas páginas resulta imposible siquiera resumir las distintas eta$\operatorname{pas}^{22}$ que generalmente la doctrina utiliza para distinguir las distintas fases que

19 Esta cifra incluye a las personas dependientes del solicitante principal como señalan PRESSÉ, D. y THOMSON, J.: «The resettlement challenge: integration of refugee from protracted refugee situations", Refuge, n. 24 (vol. 2), 2008, p. 49. Por su parte, el Gobierno de Canadá hasta el 2007 incluido da la cifra de 700.000 refugiados reasentados desde la II Guerra Mundial (Puede consultarse esta cifra en el Manual de Reasentamiento del ACNUR en el Capítulo que dedica al reasentamiento en los distintos países y que se elabora y actualiza por el Gobierno de cada uno de ellos).

20 Sobre el particular remitimos a la página del Ministerio de Ciudadanía e Inmigración de Canadá: www.cic.gc.ca.

${ }^{21}$ En España, recordemos, en la década de los noventa la mayoría de solicitantes provenía de Rumania, Cuba, Liberia, Irán, Irak y Perú. Los datos registrados por la OAR para el año 2008 señalan como principales nacionalidades a Colombia, Nigeria, Marruecos y Costa de Marfil, a diferencia de lo que ocurre con los países de la UE que apenas registran solicitudes presentadas por nigerianos o colombianos.

${ }^{22}$ Una amplia perspectiva histórica la proporciona KNOWLES, V.: Strangers at Our Gates: Canadian Immigration Policy, 1540-1997, Dundurn Press, Toronto, 1997 y GALLOWAY, D.: Immigration Law, Irwin Law, Toronto, 1997. Centrado en determinadas épocas históricas puede verse, por ejemplo, CREESE, G. "The Politics of Refugees in Canada», Deconstructing a Nation: Immigration, Multiculturalism and Racism in '90s Canada, University of Saskatchewan, Saskatoon, 1992. También puede consultarse el estudio — que, entre otros, aporta una valiosa información estadística - de ADELMAN HOWARD: "Canadian Refugee Policy in the Postwar Period: An Analysis", Refugee Policy. Canada and The United States (Ed. ADELMAN, H.), Centre for Refugee Studies, York University and Center for Migration Studies of New York, York Lanes Press Ltd., Toronto, 1991 pp. 173 y ss. 
en materia de protección de los refugiados se ha producido en Canadá, creo que a modo de resumen a trazo grueso nos sirven las siguientes palabras de JONES y BAGLAY, «time periods defined in relation to the main mileposts of immigration and refugee regulation: 1969, when Canada became a party of the Refugee Convention; 1978, when the immigration Act came into force; 1985, the year of The seminal Singh v. Canada decision which established the right of refugee claimants to an oral hearing and consequently led to a major overhaul of the refugee determination system; 1992, when another major change to inland refugee determination was introduced; and 2002, when the new Immigration and Refugee Protection Act came into force ${ }^{23}$.

A finales de los años 80 empezó a funcionar un sistema de determinación del estatuto de los refugiados completamente nuevo. Se creó el Consejo de Inmigración y Refugiados (Immigration and Refugugee Board-IRB-). Al IRB, tribunal casi judicial e independiente, se le otorgó la responsabilidad de decidir sobre las solicitudes de asilo, labor que se delegó a la División de Determinación de la condición de Refugiados según la Convención (Convention Refugee Determination Division-CRDD-), el nuevo procedimiento añadió el requisito de una vista oral para los solicitantes de asilo, fruto de la sentencia Singh v. Canada a la que nos referiremos con posterioridad.

Por último, conviene también tener presente que el Ministerio de Ciudadanía e Inmigración (CIC) no sólo es el responsable de los programas y políticas de los refugiados y de las personas en necesidad de protección sino que por lo demás se encarga de gestionar el programa canadiense de reasentamiento para lo que cuenta con un procedimiento administrativo para seleccionar a refugiados en el extranjero para su reasentamiento. Pero éstos deben cumplir con una serie de requisitos amén de estar en necesidad de protección, esto es, ser refugiado según la Convención de Ginebra o encontrarse en similares circunstancias.

\subsection{Características básicas del actual régimen jurídico del derecho de asilo en Canadá}

El actual marco legislativo en materia de asilo en Canadá viene determinado por la Immigration and Refugee Protection Act (IRPA) ${ }^{24}$ de 2002 y por la Immigration and Refugee Protection Regulations, S.O.R./2002-227, (IRPA Regula-

23 JONES, Martin y BAGLAY, Sasha: Refugee Law, Irwin Law, Canada, 2007, p. 2.

24 SC, 2001. 
tions $)^{25}$. A través de esta nueva legislación se introdujo cambios de entidad que han venido a afectar al sistema de determinación de la condición de refugiados ${ }^{26}$, amén de aquellas que han afectado a la composición de quienes intervienen en tal determinación, por ejemplo, la Refugee Protection Division (RPD) sustituyó al CRDD.

La Convención de Ginebra sobre la condición de refugiado de 1951 se ha incorporado a la IRPA (sección 96) al igual que la definición de tortura tal y como aparece en la Convención contra la Tortura y otros tratos o penas crueles, inhumanos o degradantes (sección 97 IRPA) se ha incorporado a la ley nacional ${ }^{27}$. De tal forma que aquellas personas que, en caso de ser devueltas a su país de origen, se enfrentan a un peligro de sufrir tortura, o peligra su vida o se enfrentan a un riesgo de sufrir castigo o trato cruel o inusual ${ }^{28}$ se consideran «personas necesitadas de protección $»^{29}$. Estas personas, amén de tener derecho a solicitar la residencia permanente, tienen derecho a que se les conceda los mismos derechos y los mismos beneficios que a aquellas personas que se consideran refugiadas según la Convención de Ginebra.

25 Sobre la determinación del estatuto de refugiado con anterioridad a la IRPA pueden consultarse por todos, HATHAWAY, James C.: The Law of Refugee Status, Butterworths, Canada, 1991; GOODWING-GILL, Guy: «Determining Refugee Status in Canada», Refugees, n. 38, 1987 y ZAMBELLI, Pia: The Refugee Convention: A Compendium of Canadian and American Cases, Carswell, Toronto, 1999.

26 Por ejemplo, con la entrada en vigor de la IRPA se introdujo una valoración de riesgos previa a la expulsión que permite a los solicitantes de asilo que han sido rechazados y a otras personas que no han sido admititidas, solicitar protección antes de ser expulsados de Canadá basándose en la existencia de pruebas que no fue posible o razonable facilitar en la primera vista.

27 Son numerosas las ocasiones en las que el Tribunal supremo de Canadá define las obligaciones de Canadá en el cumplimiento de los compromisos derivados de la Convención contra la Tortura. De tal forma que si bien reconoce que se puede expulsar incluso a los refugiados que representen un riesgo para la sociedad, y siempre a través de un procedimiento administrativo que sopese la gravedad de los actos cometidos y los riesgos a los que se enfrentan si se les devuelve a su país, el límite no puede ser otro para la devolución es que la persona no corra el riesgo de sufrir tortura (Suresh v. Canada (Minister of Citizenship and Immigration) (2002) 1 SCC).

${ }^{28}$ Siempre que, como establece la sección 97 (1):

«(i) la persona no sea capaz o, por miedo, no pueda aprovecharse de la protección que le ofrece dicho país,

(ii) la persona tenga que hacer frente a ese riesgo en cada parte del país, y el resto de personas en ese país no tengan que hacer frente a tal riesgo de forma general,

(iii) el riesgo no sea inherente o incidental a las sanciones impuestas por la ley, a menos que se impongan independientemente de la normativa internacional aceptada,

(iv) el riesgo no esté causado por incapacidad del país para proporcionar cuidados sanitarios y médicos adecuados».

29 Sección 97 de la IRPA. 
Cabe destacar que antes de la entrada en vigor de la IRPA la condición de refugiado se concedía de acuerdo con lo expresamente dispuesto en la Convención de Ginebra de 1951. Sin embargo, tras la entrada en vigor de la IRPA (2002) se concede la protección en cumplimiento de la Convención de Ginebra ${ }^{30}$, que se incluye literalmente (sección 96 IRPA), y de la Convención contra la Tortura y otros tratos o penas crueles, inhumanos o degradantes (sección 97 IRPA).

Debe subrayarse que la Carta canadiense de Derechos y Libertades, que se incorpora a la Constitución en $1982^{31}$, constituye un importantísimo instrumento para la protección de los refugiados ${ }^{32}$. Efectivamente, «The Canadian Charter of Rights and Freedoms have all had a significant impact on Canada's approach to refugee issues ${ }^{33}$. Son numerosos los derechos de la Carta que se invocan en el contexto de la protección de los refugiados, por ejemplo, los de la

${ }^{30}$ Remitimos para un estudio práctico y jurisprudencial sobre la aplicación de lo contenido en la Immigration and Refugee Protection Act and Regulations a la obra de WALDMAN, Lorne: Canadian Immigration \&Refugee Law Practice, Lexis, Nexos, Ontario, Canada, 2009. Puede consultarse también y, entre otros, CARASCO, E.; GALLOWAY, D.; AIKEN, S. J. y MACKLIN, A.: Immigration and Refugee Law. Cases, Materials, and Commentary, Montgomery Publications, Toronto, Canada, 2007.

31 Carta Canadiense de Derechos y Libertades, Parte 1 del Acta Constitucional, 1982, Anexo B del Acta de Canadá, 1982 (U.K.) C.11. No debe perderse de vista que, y traslado la apreciación en expresión literal del Magistrado del Tribunal Supremo de Canadá, Michel Bastarache, « la Carta, ha cambiado nuestra comprensión de la democracia canadiense y del ordenamiento jurídico; (ii) ha creado una cultura de derechos que ha dado lugar a una revisión importante de la legislación y las prácticas pasadas; y (iii) ha dado origen a numerosos debates públicos que reflejan el difícil equilibrio entre los derechos individuales y los colectivos» (BASTARACHE, Michel: «La Carta Canadiense de los Derechos y de las Libertades y la Sociedad Canadiense», Fundación Jiménez Abad, Zaragoza, 2007, p. 3). Para una mejor comprensión sobre los distintos instrumentos de protección de los derechos humanos en Canadá remitimos a WOEHRLING, J.: «Superposición y complementariedad de los instrumentos nacionales y provinciales de protección de los derechos humanos en Canadá», Derechos y Libertades en los Estados compuestos (Coord. Aparicio, M. y Castellá, J. M.), Alieter, Barcelona, 2007, p. 65 y ss. Entre las numerosas obras que analizan la Carta de Derechos remitimos entre otras, y a la bibliografía allí contenida, a ROACH, K., SHARPE, R. J. y SWINTON, K. E.: The Charter of Rights and Freedoms, Concord- Irwin Law, Ontario, 2002.

${ }^{32}$ Como botón de muestra sirva que 1985 el Tribunal Supremo en base a la Carta Canadiense de Derechos y Libertades (Singh v.Minister of Employment and immigration (1985) 1 S.C.R. 177) dictaminó que la falta de una vista oral en el procedimiento de la determinación de la condición de refugiados contravenía la Carta. Ello obligó a la modificación de la legislación al objeto de garantizar a los solicitantes la oportunidad de someterse a una vista oral lo que llevó aparejado, entre otras, la creación del Consejo de Inmigración y Refugiados -IRB-. Para un análisis detenido sobre esta trascendental sentencia remitimos, entre otros, a CARASCO, E; GALLOWAY, D; AIKEN, S. J. y MACKLIN, A.: Immigration and Refugee Law, op. cit., p. 154-160.

33 CARASCO, E.; GALLOWAY, D.; AIKEN, S. J. y MACKLIN, A, op. cit., p. 538. 
sección 7, (derecho a la vida, a la libertad y a la seguridad personal y el derecho a no ser privado de ella excepto de conformidad con los principios de la justicia fundamental $)^{34}$, sección 10 (derecho de las personas detenidas o en prisión) ${ }^{35}$, sección 12 (derecho a no ser sometido a tratos crueles e inusuales o castigo) ${ }^{36} \mathrm{y}$ sección 15 (igualdad) ${ }^{37}$.

De acuerdo con el IRPA, los miembros de la Refugee Protection Division (RPD) evaluarán si las personas en busca asilo son refugiados, según la Convención de Ginebra ${ }^{38}$, o son personas en necesidad de protección ${ }^{39}$. Una vez sus-

${ }^{34}$ Estos derechos han sido invocados en el ámbito del cumplimiento de requisitos procesales bajo los cuales se deben producir la detención y deportación (Véase, por ejemplo, Re Jaballah, 2006, F.C.J., N 110). También en numeroso casos de extradición (Por ejemplo, United Status $v$. Burns, (2001) 1 S.C.R. 283). No menos importante resultan aquellos casos que invocan estos derechos en relación con la determinación de inelegibilidad. Efectivamente, como señala JONS, M. y BAGLAY, S. «The courts have generally held that a person's ineligibility to have their refugee claim determined by the IRB (e.g., for repeat claims) does not violate section 7» (JONES, Martin y BAGLAY, Sasha: Refugee Law..., op. cit., p. 39). En esta línea véase, por ejemplo, Raza v. Canada (Minister of Citizenship and Immigration,), 1999, 2 F.C. 185.

35 Esta sección 10 reconoce el derecho de las personas detenidas o en prisión a ser informadas sin dilaciones de las razones de tal detención y a ser informadas del derecho a un abogado y del derecho a darle instrucciones al mismo, así como del derecho al habeas corpus para mantener la validez de la detención y de ser puesto en libertad si la detención no es legal. Como también han puesto de manifiesto JONES, M. y BAGLAY, S.: «Much of the jurisprudence in the refugee matters centres around an analysis of the timing of of the arrest or detention and nature of immigration procedures which give rise to a right to counsel» (JONES, Martin y BAGLAY, Sasha: Refugee Law..., op. cit., p. 40).

36 Esta sección ha sido frecuentemente invocada, por ejemplo, en casos de deportación (Sinnappu v. Canada (Minister of Citizenship and Immigration), 1992, S.C.J., N 27) y de detenciones prolongadas de extranjeros y residentes permanentes under nacional security provisions (véase, por ejemplo, Almrei v. Canada (Minister of Citizenship and Immigration), 2004, F.C.J. N 509 o Re Jaballah, cit.).

37 Esta sección viene a disponer que «Toda persona es igual ante y bajo la ley y tienen derecho a igual protección y beneficio sin discriminación y, en particular, a no ser discriminadas por motivos de raza, origen nacional o étnico, color, religión, sexo, edad o discapacidad mental o física». En este ámbito resulta de especial interés la sentencia de Re Jaballah $v$ Canada, vid. nota 21 y el caso CharKaoui v. Canada (Minister of Citizenship and Immigration), 2007, S.C.J., N 9).

38 Conviene hacer notar que Canadá no ha ratificado la Convención de 1954 relativa a la Condición de los Apátridas, sin embargo, es signataria de la Convención de 1961 sobre la reducción de la apatridia. Todos los solicitantes de Asilo, independientemente de si son apátridas, tienen los mismos derechos y sus casos son tratados individualmente según sus propios meritos.

39 Remitimos al interesante artículo de ROUSSEAU, C., CREPEAU, F., FOXEN, P., y HOULE, F.: «The Complexity of Determining Refugeeehood: A Multidisciplinary Analysis of The Decision-Making Process of The Canadian Immigration and Refugee Board", Journal of Refugee Studies, 15, 2002, p. 43 y ss.

(C) UNED. Revista de Derecho Político

N. ${ }^{\circ} 78$, mayo-diciembre 2010, págs. 43-93 
tanciado el procedimiento, el RPD del IRB puede bien conceder la condición de refugiado según la Convención de Ginebra bien conceder la protección o, por el contrario, rechazar tales solicitudes ${ }^{40}$. La combinación de los motivos que dan lugar al reconocimiento de la condición de refugiados según la Convención de Ginebra, así como los otros motivos que dan lugar al reconocimiento de otro tipo de protección, vienen a denominarse motivos consolidados.

Quienes demandan asilo solo tienen que presentar una única solicitud de protección para obtenerla, en su caso, por los motivos contenidos en la Convención de Ginebra o por los otros motivos. Efectivamente, en consonancia con lo dispuesto en la IRPA, los miembros de la RPD deberán evaluar si las personas que demandan asilo son refugiados según la Convención, o personas que necesitan protección. La decisión es adoptada según las pruebas presentadas tras una vista $^{41}$.

Las solicitudes de asilo se pueden presentar en cualquier punto de entrada al país (aeropuerto, puerto o puesto fronterizo ${ }^{42}$ ) o en la oficina local del Citizenship and Immigration Canada (CIC). Amén de determinadas comprobaciones (médicas y de seguridad), un funcionario de inmigración entrevistará al solicitante al objeto de determinar si la solicitud se puede remitir al IRB.

Por lo que afecta al reconocimiento de algunos de los derechos anejos a tal solicitud cabe destacar que los solicitantes de asilo pueden representarse a sí mismos en una vista o contar con la asistencia de un consejero a lo largo de todo el proceso. Pueden contactar con la oficina de apoyo legal en el lugar en el que está tramitándose su solicitud. Pueden indicar si van a necesitar intérpretes $^{43}$. Éstos corren a cargo del Immigration and Refugee Board (IRB). El alojamiento para aquellas personas que solicitan asilo constituye una responsabilidad provincial $^{44}$. El alojamiento no es gratuito pero el precio del alquiler está con-

${ }^{40}$ No obstante, tal y como dispone la sección 25 de la IRPA, el Ministerio tiene competencia para conceder exenciones en relación con los requisitos que contiene la IRPA, o conceder la residencia permanente, por motivos humanitarios y compasivos a los demandantes de asilo cuya solicitud no haya sido admitida o a los que se les haya denegado el asilo.

${ }^{41}$ Vista que puede ser completa, por vía rápida o a través de un proceso acelerado.

42 A estos efectos, debe tenerse presente el Acuerdo de Tercer País Seguro (STCA) entre Canadá y EEUU, firmado el 5 de diciembre de 2002, y que entró en vigor en diciembre de 2004. El principio general que rige en el STCA exige que el primer país al que llega el solicitante asume la responsabilidad de decidir sobre la solicitud de refugio, salvo que el solicitante tenga derecho a una excepción en virtud de tal acuerdo.

43 Sobre el derecho a intérprete remitimos, entre otras, a Kovacs v. Canada (Minister of Citizenship and Immigration), 2003, F.C.J., N.25 (T.D); o Mohammadian v. Canada (Minister of Citizenship and Immigration), 2001, F.C.J., N.916 (C.A.).

${ }_{44}$ No existe un programa federal que proporcione alojamiento. 
siderablemente subvencionado. Pueden solicitar asistencia social para cubrir necesidades básicas. Ésta las proporcionan los gobiernos provinciales y municipales y las tarifas de la asistencia social varían de un sitio a otro. Aquellas personas cuyas solicitudes de asilo estén siendo tramitadas en el IRB y que en materia sanitaria no tengan una póliza y no puedan costearse servicios básicos y de emergencia pueden solicitar al CIC una cobertura sanitaria federal provisional que cubre los servicios sanitarios de emergencia. Los niños en edad escolar tienen derecho a asistir al colegio y los demandantes de asilo pueden solicitar una autorización para trabajar. Los permisos de trabajo se conceden por un período de 24 meses.

Si se deniega el derecho de asilo, la sentencia se hará efectiva y la persona que solicita el derecho de asilo deberá abandonar Canadá en 30 días, no obstante se prevé la posibilidad de recurrir la decisión en un plazo de 15 días. En el supuesto de que se conceda el asilo u otra protección, las personas a las que se les concede gozan de la condición de "personas protegidas» y se las protege contra una posible devolución ${ }^{45}$ amén de reconocérseles un conjunto de derechos. Las personas protegidas tienen derecho a solicitar al CIC la residencia permanente dentro de los 180 días de la resolución ${ }^{46}$ y, posteriormente, la ciudadanía tras haber residido en Canadá durante tres años ${ }^{47}$.

De forma muy resumida no debe perderse de vista, como también recuerdan Carasco, Galloway, Aiken y Macklin que, «The Immigration and Refugee Board (IRB) es un tribunal independiente compuesto de tres divisiones. The immigration Division (ID) «adjudicates immigration officers' reports on inadmissibility of individual non-citizens, and reviews detention orders. The immigration Appeal Division (IAD) hears appeals from refused applications for sponsorship of family class members, and certain removal orders. The Refugee Protection Di-

45 Sección 115(1).

46 Cabe señalar que también se prevé la posibilidad de expedir un permiso de residencia temporal en virtud de las disposiciones de la designación de Clase Residente Temporal para aquellas personas que se consideran refugiados fuera de Canadá y que necesitan protección urgente. Una vez en Canadá pueden solicitar un permiso de residencia permanente A juicio de A. BROUWER, el estatuto de residente permanente debiera ser automáticamente otorgado a los refugiados sin necesidad sin necesidad de que lo soliciten en el plazo de los 180 días desde la resolución (BROUWER, A.: «Permanent protection: why Canada should grant permanent residence automatically to recognized refugees", Refuge, 22, vol. 2, 2005, p. 88).

${ }^{47}$ Como residentes permanentes las personas protegidas tienen derecho, entre otros, a los siguientes beneficios: cobertura sanitaria, el derecho a vivir, trabajar, y estudiar en cualquier parte de Canadá y recibir protección de acuerdo con la ley canadiense y la Carta canadiense de Derechos y Libertades. 
vision (RPD) determines applications for refugee status by inland refugee claimants. The Federal Court judicially reviews these various immigration decisions, though it imposes a leave requirement on certain classes of cases. The Federal Court of Appeal will only entertain appeals from the Federal Court where the latter certifies a question of general importance arising from the

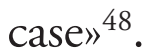

La IRPA regula expresamente las causas de exclusión a la hora de examinar las solicitudes de protección, prevé las causas de denegación, ${ }^{49}$ de cese y de revocación de la condición de refugiados. En cuanto a las causas de exclusión, se aplican los art. 1.F y E de la Convención de Ginebra (sección 98 de la IRPA) al analizar las solicitudes.

El ordenamiento prevé el cese de la protección en dos momentos: La RPD del IRB puede decidir el día de la vista ${ }^{50}$, cuando se evalúa cuál es el temor a la persecución de forma fidedigna, que se ha producido un cambio en las circunstancias. También se prevé que el Ministerio pueda solicitar el cese de la protección a un refugiado una vez que dicha persona haya recibido el estatuto de refugiado ${ }^{51}$. Esto ocurre de forma muy excepcional. A quienes se les haya cesado

48 CARASCO, E.; GALLOWAY, D.; AIKEN, S. J. y MACKLIN, A.: Immigration and Refugee Law, op. cit., p. 24.

49 Sección 108 de la IRPA «Una solicitud será rechazada, y una persona no será considerada como refugiado o persona que necesite protección, de acuerdo con la Convención, si se cumplen cualquiera de las siguientes circunstancias:

a) la persona haya decidido volver a aceptar de forma voluntaria la protección que ofrecía su país de nacionalidad;

b) la persona haya readquirido voluntariamente su nacionalidad;

c) la persona haya adquirido una nueva nacionalidad y disfrute de la protección que le ofrece ese nuevo país;

d) la persona se haya reasentado de forma voluntaria en el país que dejó o del que ha permanecido alejado y respecto al cual dicha persona solicitó refugio y protección en Canadá; $\mathrm{O}$

e) las razones por las que la persona buscó refugio y protección hayan dejado de existir.

${ }^{50}$ Los representantes del ACNUR supervisan el proceso relacionado con la protección de los Refugiados en Canadá y presencian las vistas de la RPD sin limitación alguna atendiendo las competencias del propio ACNUR.

${ }^{51}$ La sección 108 preceptúa literalmente que: «(1) Una solicitud de protección será rechazada, y una persona no será considerada como refugiada o persona necesitada de protección, de acuerdo con la Convención, si se cumple con las siguientes circunstancias:

a) la persona haya decidido volver a aceptar de forma voluntaria la protección que le ofrecía su país de nacionalidad;

b) la persona haya readquirido voluntariamente su nacionalidad,

c) la persona haya adquirido una nueva nacionalidad y disfrute de la protección que le ofrece ese nuevo país, 
en su condición de refugiado ${ }^{52}$ pueden solicitar del Tribunal Federal que se revise de forma judicial tal decisión.

También la IRPA regula la posibilidad de revocar la condición de refugiado. El Ministerio podrá presentar una solicitud para revocar la protección cuando la decisión de otorgar tal estatuto se hubiera adoptado como resultado de la falsificación u ocultación, directa o indirecta, de pruebas materiales relacionadas con un asunto relevante. En tales supuestos contra tal decisión cabe, como en el supuesto anterior, recurrir ante el Tribunal Federal.

\subsection{Condiciones, requisitos y financiación de los Programas de Reasentamiento}

\subsubsection{Personas que pueden ser objeto de Reasentamiento y los requisitos que deben reunir para poder ser reasentadas.}

El reasentamiento en Canadá sólo se aplica a personas extranjeras que estén fuera de Canadá, quieran establecer su residencia permanente en Canadá, no tengan posibilidad razonable de encontrar una solución duradera fuera de $\mathrm{Ca}$ nadá y, evidentemente, que necesiten protección, es decir, que pertenezcan a la doble categoría de Refugiados en el sentido de la Convención de Ginebra ${ }^{53}$ o de personas que se encuentran en similares circunstancias ${ }^{54}$ :

«For the purposes of subsection 12(3) of the Act, a person in similar circumstances to those of a Convention refugee is a member of one of the following humanitarian-protected persons abroad classes:

(a) the country of asylum class; or

(b) the source country class. ${ }^{55}$

d) la persona se haya reasentado de forma voluntaria en el país que dejó o del que ha permanecido alejado y respecto del cual dicha persona solicitó refugio y protección en Canadá; o

e) las razones por las que la persona buscó refugio y protección hayan dejado de existir.

(2) A través de su solicitud al Ministerio, la División de Protección de Refugiados podrá determinar que la protección a un refugiado, contenida en la subsección 95(1), ha terminado por cualquiera de los motivos detallados en la subsección (1)».

52 Sobre cuándo un refugiado constituye un peligro para la seguridad de Canadá remitimos por todas a la interesante Sentencia Suresh v. Canada (Minister o Citizenship and Immgration), 20021 SCR 3.

53 «The Convention refugees abroad class is prescribed as a class of persons who may be issued a permanent resident visa on the basis of the requirements of this Division» (sección. 144 del Reglamento).

54 Véase sección 146 a 151 del Reglamento.

55 Sección 146 del Reglamento. 
En consecuencia, tres son las categorías que se utilizan generalmente para el reasentamiento:

- Refugiados según la Convención de Ginebra que se encuentran fuera de su país de origen ${ }^{56}$.

- Personas que se encuentran fuera de su país de nacionalidad y/o de residencia, que no son refugiados según la Convención pero que se ven afectados por graves conflictos o son víctimas de violaciones masivas de los derechos humanos ${ }^{57}$. Esta categoría recibe el nombre de clase de País de Asilo.

- Personas que viven en determinados países que se encuentran en situación asimilable a la de un refugiado como consecuencia de una guerra civil o un conflicto armado y donde no se respetan los derechos humanos fundamentales. Esta categoría recibe el nombre de clase de País de Origen. El país de origen, por mandato de la sección 149 del Reglamento, debe cumplir con una serie de requisitos al igual que las personas que pertenezcan a esta categoría ${ }^{58}$.

En definitiva, las personas que no son refugiadas según la Convención de Ginebra y que pertenecen a la clase de país de asilo o de país de origen se integran a efectos del Reasentamiento en la categoría de «Personas Protegidas en el Extranjero por Motivos Humanitarios». Cabe añadir, además, que la IRPA ha venido a introducir un procedimiento específico para aquellas personas que, bien sean Refugiados según la Convención de Ginebra, bien sean Personas Protegidas en el Extranjero por Motivos Humanitarios, que se encuentren en «necesidad urgente de protección» o se encuentran en circunstancias «vulnerables».

Tal y como se define en la sección 138 del Reglamento, en «necesidad de urgente protección» se encuentra un refugiado según la CG de 1951 o aquellas

${ }^{56}$ Esto es, a quien debido a fundados temores de ser perseguido por motivos de raza, religión, nacionalidad, pertenencia a determinado grupo social u opiniones políticas, se encuentre fuera del país de su nacionalidad y no pueda o, a causa de dichos temores, no quiera acogerse a la protección de tal país; Asimismo, se considera refugiado a quien, careciendo de nacionalidad y hallándose, a consecuencia de tales acontecimientos, fuera del país donde antes tuviera su residencia habitual, no pueda o, a causa de dichos temores, no quiera regresar a él.

57 Véase. sección 147 del Reglamento.

58 Éstas deben cumplir una de las siguientes condiciones: encontrarse seria y personalmente afectada por una guerra civil o un conflicto armado en su país de origen; haber estado o estar detenido, encarcelado o condenado con cargos o sujetos a cualquier otro tipo de control penal de acuerdo con una ley que en Canadá fuera considerada como ejercicio legítimo de la libertad de expresión o de un derecho civil o satisfacer la definición de refugiado según la Convención, salvo por la condición de estar fuera de su país de nacionalidad o residencia habitual. 
personas que pertenecen a la clase de país de asilo o país de origen «cuya vida, libertad o seguridad física está bajo una amenaza inmediata y, en caso de que no se la proteja, es probable que dicha persona sea: a) asesinada; b) sometida a actos de violencia, tortura, abusos sexuales o encarcelamiento arbitrario; o c) devuelta a su país de nacionalidad o de residencia habitual». La denominación de «vulnerables», tal y como se recoge en el último párrafo de la misma sección 138, se aplica a aquellas personas que por su circunstancias particulares tienen que enfrentarse a un elevado riesgo contra su seguridad física y necesitan una protección mayor que el resto de solicitantes. Para estos supuestos se expide un permiso de Residente Temporal Protegido. Cuando llegan a Canadá tienen que solicitar la residencia permanente y se les exime del requisito de establecerse con éxito en Canadá tal y como establece la sección 139 (2) del Reglamento.

En cuanto a los criterios que se siguen para el reasentamiento, el sistema distingue entre los criterios de idoneidad y los de admisibilidad. En cuanto a los primeros, Canadá, como expresamente recuerda el Manual de Reasentamiento, únicamente considerará una solicitud de reasentamiento si ha sido remitida por «El ACNUR; Otra (designada) "organización de referencia"59; un patrocinador privado (es decir, si ya tiene un patrocinador privado aprobado)»y, efectivamente, "Solo en ciertas áreas geográficas los solicitantes pueden pedir el trámite directamente a la oficina canadiense de visados sin una referencia».

A ello se añade el hecho de que los solicitantes deben demostrar potencial para llegar a valerse por sí mismos en Canadá en un periodo de tres a cinco años ${ }^{60}$, salvo que el funcionario de los visados determine que la persona se encuentre en urgente necesidad de protección en cuyo caso se le exime del cumplimiento de tal aptitud.

En todo caso, para que una persona refugiada sea aceptada por Canadá debe pasar un examen médico que determine que el solicitante no padece un problema médico que represente un peligro para la salud pública o la seguridad del país; una revisión de antecedentes penales y una revisión de seguridad ${ }^{61}$.

59 La sección 143 del Reglamento aclara que la organización de remisión ha de ser el ACNUR u otra organización con la que el Ministerio de Ciudadanía e Inmigración haya llegado a un Memorando de Entendimiento.

60 Para valorar tal potencial los oficiales encargados del visado deben tener en cuenta factores tales como «la educación, la presencia de una red de apoyo en Canadá (familia o patrocinadores), experiencia de trabajo y calificaciones, habilidad para aprender a hablar inglés o francés y otros factores personales como la iniciativa».

${ }_{61}$ Como se reitera en el Manual de Reasentamiento «Canadá no aceptará a combatientes que hayan participado en crímenes de guerra o crímenes de lesa humanidad. De conformidad con la Ley de Inmigración y Protección del Refugiado, son inadmisibles los oficiales superiores, inclusi- 
Conviene añadir que los solicitantes de reasentamiento además de demostrar la necesidad de protección, la capacidad de establecerse en Canadá y de satisfacer los requisitos de admisión (control médico, de seguridad y de criminalidad), con las excepciones ya expuestas deben, por lo demás, demostrar disponibilidad de recursos económicos para ser reasentados y ello necesariamente requiere un respaldo financiero y éste se puede producir ya sea a través de patrocinio público, privado o conjunto. Éste, a mi juicio, constituye uno de los aspectos más característicos del modelo canadiense de reasentamiento.

\subsubsection{La financiación (pública, privada o conjunta) como elemento basilar de los programas de Reasentamiento en Canadá}

Si tuviera que elegir un elemento que caracterice el reasentamiento de refugiados en Canadá, sin lugar a dudas, elegiría el peso que adquiere la existencia necesaria de un patrocinador (público o privado) para hacer efectivo el reasentamiento. De hecho, como sinópticamente describen Jones y Baglay, «El reasentamiento se compone de dos procesos temporales y geográficos distintos: (1) el proceso inicial en Canadá, por medio del cual una solicitud se hace a través de un posible patrocinador privado de un refugiado y la solicitud es entonces revisada y aprobada por un funcionario del CIC; y (2) el proceso de monitorización y selección de refugiados patrocinados en el extranjero, que determinará el cumplimiento de los requisitos del individuo o de su familia para su reasentamiento en Canadá. Sólo cuando ambos pasos del proceso se hayan completado y el refugiado y la entidad patrocinadora encajen, el refugiado podrá reasentarse en Canadá» ${ }^{62}$.

Efectivamente, la cuota anual de reasentamientos se hace depender de un programa de asistencia financiera cuyo patrocinador, ya sea público o privado, es el responsable de prestar asistencia financiera al refugiado durante un período de tiempo (un año, aunque excepcionalmente puede tener una duración de tres años máximo) y de ayudarle a integrarse en Canadá. Como tantas veces se subraya, «Como norma, todos los refugiados reasentados deben estar patrocinados, ya sea por una figura gubernamental o privada. Sin embargo, los refugiados que posean suficientes recursos económicos propios también pueden ser reasentados como inmigrantes económicamente independientes» ${ }^{63}$.

ve ex oficiales u oficiales militares superiores en activo, de ciertos regímenes y los individuos que militan en organizaciones que propugnan la violencia».

62 JONES, Martin y BAGLAY, Sasha: Refugee Law, op. cit., p. 185.

${ }^{63}$ Ibidem, p. 187. 
El patrocinio de carácter gubernamental implica que el reasentamiento se financia totalmente por el Gobierno de Canadá o, en su caso, por el de Québec. La ayuda de los refugiados patrocinados por el Gobierno se dispensa, una vez que éstos llegan a Canadá, a través de las agencias no gubernamentales del CIC.

En cuanto a los patrocinadores privados el reglamento distingue tres categorías de patrocinio: Titulares de Convenio de Patrocinio -SAH- y los grupos que lo constituyen, Patrocinios comunitarios y el denominado Grupo de Cinco (grupo de cinco o más ciudadanos canadienses o residentes permanentes).

El reglamento regula de forma detallada distintos aspectos relativos a la forma de solicitar convertirse en estos grupos, requisitos que deben concurrir en los patrocinadores ${ }^{64} \mathrm{y}$ en el acuerdo de patrocinio (condiciones, obligaciones, durabilidad, etc.), así como algunas de las condiciones que se exigen para ser patrocinador ${ }^{65}$. En esta línea, por ejemplo, destacan las causas que inhabilitan para ser patrocinador privado (detenidos, personas condenadas por asesinato o delito grave cometido dentro o fuera de Canadá durante los primeros cinco años después que la sentencia entrara en vigor —a menos que fuera perdonado o absuelto- - personas sujetas a órdenes de expulsión, personas sujetas a la revocación de la ciudadanía, y aquellas que no hayan cumplida con el pago de obligaciones impuestas por un tribunal) ${ }^{66}$.

En todo caso, cabe señalar que los Titulares de Convenio de Patrocinio - $\mathrm{SAH}$ - (organizaciones religiosas, étnicas, comunitarias y de servicios), en virtud de haber firmado un acuerdo con el CIC, no tienen que superar ningún

${ }^{64}$ En esta línea debemos recordar que la entidad que patrocina debe estar situada o tener representantes en la comunidad donde se supone residirá el refugiado, que el patrocinador posea suficientes medios y recursos para satisfacer las necesidades de los refugiados y proporcionar apoyo adecuado y que el patrocinador no sea y no esté constituido por un individuo o una organización que fuera parte de una empresa que no haya estado al corriente de pagos y siga sin estarlo.

65 Sección 152 a 158 del Reglamento.

66 Tal y como dispone la sección 156 (1): «Les personnes suivantes sont inhabiles à être parties à un parrainage : a) la personne qui a été déclarée coupable au Canada de meurtre ou de l'une ou l'autre des infractions qui figurent àl'annexe I ou II de la Loi sur le système correctionnel et la mise en liberté sous condition, qu'elle soit punissable par procédure sommaire ou par mise en accusation, à moins qu'une période de cinq ans suivant l'expiration de la peine d'emprisonnement infligée aux termes du Code criminel ne se soit écoulée; b) la personne qui a été déclarée coupable d'une infraction à l'étranger qui, si elle était commise au Canada, constituerait une infraction visée à l'alinéa $a$ ), à moins qu'une période de cinq ans suivant l'expiration de la peine d'emprisonnement infligée aux termes du droit étranger ne se soit écoulée; $c$ ) la personne qui manque à une obligation alimentaire imposée par un tribunal; d) la personne qui fait l'objet d'une mesure de renvoi; e) la personne qui fait l'objet d'une procédure d'annulation sous le régime de la Loi sur la citoyenneté; f) la personne qui est détenue dans un pénitencier, une prison ou une maison de correction».

(C) UNED. Revista de Derecho Político 
proceso de evaluación de aprobación cada vez que quieran reasentar a un refugiado. Por su parte, el Patrocinio comunitario está abierto a cualquier organización, constitutiva o no y con o sin ánimo de lucro, y a diferencia de los SAH tiene que pasar a evaluación sus planes financieros y de asentamiento cada vez que quieran traer refugiados a Canadá y tienen un límite de solicitudes de patrocinio. Cabe un patrocinio conjunto entre los $\mathrm{SAH}$ y los patrocinadores comunitarios para asistir a un refugiado o a grupos de refugiados concretos. Los Grupos de Cinco o más ciudadanos o residentes permanentes pueden patrocinar refugiados para su reasentamiento, cumpliendo una serie de requisitos. Pero quizás lo más relevante es que no todos los miembros están obligados a contribuir económicamente. La totalidad del grupo debe presentar un plan de asentamiento y una evaluación completa de su estado financiero ${ }^{67}$.

Cabe hacer referencia al patrocinio de Asistencia Conjunta (JAS). Este patrocinio financia programas destinados a refugiados con necesidades especiales y que requieren mayor ayuda que el resto ${ }^{68}$. En este tipo de patrocinio JAS comparten las responsabilidades del patrocinio el Gobierno, que asume la responsabilidad financiera, y un grupo patrocinador privado, que es el que se compromete a garantizar la integración del refugiado.

Dicho todo lo anterior, no cabe perder de vista que la solicitud de patrocinio es una parte del proceso de reasentamiento en Canadá y, en consecuencia, el sistema prevé un procedimiento para emparejar a los solicitantes extranjeros y a los patrocinadores.

${ }^{67}$ A estos efectos resultan de interés las guías -Guía para la solicitud de Patrocinio para Refugiados: Grupo de Cinco y la Guía para el Patrocinio Privado- que se encuentran online en el CIC: www.cic.gc.ca.

${ }^{68}$ La sección 157 establece que, «(1) Si l’agent estime que la personne qui appartient à la catégorie établie à la section 1 a des besoins particuliers, le ministère doit tenter de trouver un répondant afin de rendre disponible l'aide financière du gouvernement du Canada aux fins de parrainage. Le répondant n'est pas tenu de respecter les exigences financières visées à l'alinéa 154 (1) a). (2) (2) Pour l'application du présent article, a des besoins particuliers la personne qui a un plus grand besoin d'aide pour son établissement que d'autres demandeurs de protection outre-frontières, du fait de sa si situation particulière, notamment : a) un grand nombre de membres de la famille; $b$ ) un traumatisme découlant de la violence ou de la torture; $c$ ) une invalidité physique ou mentale; $d$ ) les effets de la discrimination systémique. 


\subsubsection{Aspectos básicos de la tramitación y sustanciación del procedimiento para proceder al reasentamiento}

Señalábamos con anterioridad que resulta común distinguir en el proceso de reasentamiento dos fases: una de carácter territorial y otra en el extranjero. En este proceso, en su globalidad, las oficinas de visados adquieren un peso realmente trascendente especialmente en lo que afecta la admisión, tramitación y ejecución de las solicitudes de reasentamiento.

En el reasentamiento los trámites se realizan en las Embajadas en Canadá en los distintos lugares del mundo. Las presentaciones de solicitud se realizan con carácter general directamente en la oficina canadiense de visados que se encuentre en el lugar de residencia del solicitante y debe ir acompañado o bien por una recomendación de ACNUR o bien con el compromiso de un patrocinio privado. No obstante, en casos excepcionales, el CIC puede designar ciertas regiones como zonas de acceso directo donde se exime a los solicitantes del requisito de presentar la recomendación o patrocinio privado. Comparto con Jones y Baglay la apreciación de que «La ausencia de oficinas en los países de origen pueden crear obstáculos prácticos que dificulten el acceso de los solicitantes de reasentamiento. La necesidad de viajar a otro país puede impedir que muchos solicitantes lo hagan como consecuencia de los gastos prohibitivos del viaje, los peligros o la incapacidad de abandonar su país de residencia, etc., viajar a otro país también puede requerir que el solicitante obtenga un visado para poder llegar al país en el que está situada la embajada ${ }^{69}$.

En la solicitud que debe presentar el solicitante se le demanda que proporcione información detallada sobre sí mismo, sobre los miembros de su familia, personas dependientes de facto del solicitante, descripción de la situación de persecución, capacidad de su gobierno para protegerle y preguntas destinadas a averiguar la capacidad del solicitante para su adaptación en Canadá (vínculos familiares con Canadá, experiencia laboral, conocimientos de idiomas, etc.).

Un funcionario del departamento de visados entrevista al solicitante, salvo que el funcionario renuncie a la misma ${ }^{70}$, y determina —a través del procesamiento de las pruebas, documentos presentados y la entrevista ${ }^{71}$ - si la persona

69 JONES, Martin y BAGLAY, Sasha: Refugee Law, op. cit., p. 170.

70 Por ejemplo, se puede renunciar a la entrevista cuando se identifica una necesidad urgente de protección o en aquellos casos que están sobradamente documentados

${ }^{71}$ Resulta de enorme interés la jurisprudencia que ha diferenciado distintos niveles de protección en el procedimiento en función de que la solicitud se presente dentro del territorio o en el extranjero (véase, por ejemplo, Zia v. Canada (Minister of Citizenship and Immigration), 1997, F.C.J., N. 784. 
identificada cumple con los requisitos de idoneidad y admisibilidad para el reasentamiento, en cuyo caso se aportan el reconocimiento médico y se realizan las oportunas comprobaciones de antecedentes penales y de seguridad.

En fin, la decisión final de aceptación o de rechazo la adopta el funcionario de visados basándose en los resultados de la entrevista, el reconocimiento médico y comprobación de los antecedentes penales y de seguridad. No obstante, no cabe olvidar la importancia que adquiere para aceptar favorablemente la solicitud de reasentamiento una valoración positiva sobre la capacidad potencial del solicitante para instalarse con éxito en Canadá y poder dejar de depender de la asistencia social en un período de tiempo limitado. Para ello, el funcionario debe tener en cuenta una serie de factores a la hora de realizar tal evaluación ${ }^{72}$. Una valoración negativa puede constituir un motivo de rechazo del reasentamiento solicitado por parte del funcionario. No obstante, cabe subrayar que, a diferencia de lo que ocurría en la anterior legislación, a partir de 2002 con la vigencia de la IRPA se da prioridad a la necesidad de protección antes que a la capacidad de adaptación del refugiado. Ello se aprecia fundamentalmente en el hecho de que se exime de este requisito a quienes se encuentran en necesidad urgente de protección ${ }^{73} \mathrm{o}$ en situación de especial vulnerabilidad así como la posibilidad, antes de rechazar a un solicitante para su reasentamiento, de evaluar esa capacidad en fundición de que esa instalación puede producirse con éxito en el supuesto de que se le pueda proporcionar una ayuda extra ${ }^{74}$. En fin, como en tantas ocasiones ha puesto de manifiesto la doctrina, y conforme a la anterior Ley de Inmigración, la Jurispruden$\mathrm{cia}^{75}$ ha dado sobradamente muestra de juicios considerados arbitrarios y subjetivos cuando se ha procedido a evaluar esa «idoneidad». Actualmente la capacidad de establecerse se utiliza en muy pocas ocasiones como razón para el rechazo ${ }^{76}$.

72 Recursos económicos; presencia de familiares en Canadá o de un patrocinador en la comunidad donde se producirá el reasentamiento; capacidad para encontrar trabajo en Canadá dada su educación, experiencia laboral, capacidades y capacidad para aprender a comunicarse en una de las lenguas oficiales. Véase al respecto el Manual de Procedimientos y Criterios para Determinar la Condición de Refugiado en el Extranjero (Overseas Selection and Processing of Convention Refugees Abroad Class and Members of the Humanitarian-Protected Persons Abriad Classes, www.cic.gc.ca).

73 La política de Canadá, tal y como recuerda el capítulo de país del manual de reasentamiento del ACNUR es tratar, en la medida de lo posible, de que la persona esté en camino hacia Canadá entre tres a cinco días a partir de la referencia del ACNUR.

74 Véase el Manual de Procedimientos y Criterios para Determinar la Condición de Refugiado en el Extranjero.

75 Vandi v. Canada (Minister of Citizenship and Immigration), 2002, F.C.J., N. 692; Chand v. Canada (Minister of Citizenship and Immigration), 1999, F.C.J., N. 319; Ahmad v. Canada (Minister of Citizenship and Immigration), 1997, F.C.J., N. 1461.

76 PRESSÉ, D. y THOMSON, J., op. cit., p. 50. 
Si la petición se rechaza, se informa al solicitante de la decisión negativa y de las razones que fundamentan tal rechazo. Si en caso contrario se acepta, amén de lo que ya se ha señalado, corresponde también a la oficina de visados, revisar las solicitudes de préstamos para gastos de traslado, expedir el visado de residente permanente, realizar gestiones del viaje, en su caso, en colaboración con la OIM, proporcionar a los refugiados orientación e información del viaje, informar de la fecha y lugar en que los refugiados llegan a Canadá.

\subsubsection{Algunas consideraciones sobre las políticas de reasentamiento en Canadá}

Llegados a este punto parece claro que tras la entrada en vigor de la IRPA y de la IRPA Regulations, Canadá ha puesto especial énfasis en determinados aspectos que inciden positivamente en el sistema de protección de los refugiados.

En primer lugar, recordemos, con carácter previo, que el Gobierno de Canadá realiza una planificación plurianual del reasentamiento a largo plazo, lo que contribuye a una administración más eficaz de los recursos y de las prioridades en materia de protección. Ello, con independencia de que el Ministerio de Ciudadanía e Inmigración establece un objetivo de reasentamiento de carácter anual para los refugiados ayudados por el Gobierno, tras realizar consultas internas y tras consultar a los gobiernos provinciales ${ }^{77}$, ONGs y el ACNUR. El objetivo anual se distribuye, como señala el Gobierno, entre las oficinas de visados basándose en las necesidades de reasentamientos estimadas.

Conviene en esta línea matizar que Québec tiene competencia para decidir y proceder al reasentamiento de refugiados, en ningún caso para la determinación del estatuto de refugiado o de situaciones asimilables, ni en el interior, ni en el exterior. Si en el procedimiento de la determinación del estatuto de refugiados el Gobierno de Canadá es el competente, no ocurre lo mismo cuando de lo que se habla es de integración o de reasentamiento en Québec. Efectivamente para ser seleccionado por Québec el estatuto de refugiado tiene que haber sido reconocido previamente por el Gobierno de Canadá ${ }^{78}$ aunque es Québec quien se-

77 No cabe perder de vista que los gobiernos provinciales son responsables, por ejemplo, de la atención sanitaria y de los servicios sociales. En aquellos supuestos en los que se decida reasentar a personas con necesidades médicas especiales y que requieren tratamiento médico costoso debe ser previsto con anterioridad y mostrar su acuerdo el gobierno provincial, así garantiza la atención adecuada en el lugar que lo pueda proporcionar.

78 A Canadá también corresponde determinar si, debido a consideraciones humanitarias, una solicitud de residencia permanente puede tratarse en Canadá. Si Canadá accede a tal petición la 
lecciona a los refugiados que serán por ello acogidos, previa comunicación al Gobierno de Canadá sobre la cantidad y la procedencia de los refugiados y las personas en situación similar que, una vez seleccionados, serán acogidos en Québec. Al Gobierno de Québec corresponde examinar la candidatura de los refugiados según las distintas capacidades de integración así como la selección de los mismos. La selección siempre tiene en cuenta el grado de desamparo del candidato y su capacidad para integrarse en la sociedad quebéquense.

En segundo término, se aprecia un cambio de entidad en cuanto que se pone un mayor acento en la protección del refugiado a reasentar en lugar de la capacidad de asentarse e integrarse con éxito en Canadá. En esta línea se pone un especial énfasis en el tratamiento acelerado de aquellos casos que requieren una protección urgente y las personas especialmente vulnerables.

El uso estratégico del reasentamiento como instrumento que permite un tratamiento eficaz del mismo para determinados grupos de personas, se percibe como una herramienta eficiente que permite abordar y ofrecer soluciones a determinados grupos de refugiados de larga duración de forma multifacética. Canadá, como perfectamente describen Pressé y Thomson, está tratando de mejorar los Programas de reasentamiento para contribuir a los objetivos de la Agenda para la Protección, entre los que se encuentra el de centrar una parte de los esfuerzos en el ámbito del reasentamiento en aquellas situaciones prolongadas de refugio específicas. Efectivamente, el Ministerio de Ciudadanía e Inmigración ha trabajado activamente en algunas de las situaciones identificadas por el ACNUR en «La Situación de los Refugiados en el Mundo» (2006). Esta modificación de las políticas canadienses dio como resultado, tal y como expresan los autores, un cambio significativo en la población de refugiados reasentados en Canadá. En primer lugar, según ellos, el cambio ha permitido a muchas más personas con importantes requisitos médicos ser elegidos para el reasentamiento. En segundo término, el grupo del que Canadá selecciona a los refugiados ha cambiado incluyéndose ahora grupos de refugiados en África, Oriente Medio y Asia y «dado que algunos de estos grupos provienen de contextos políticos, económicos y sociales completamente diferentes, actualmente muchos refugiados presentan distintas necesidades en el asentamiento, que incluyen requisitos especiales, resultados de años de traumas o torturas» ${ }^{79}$.

En tercer término, la reagrupación familiar en el reasentamiento constituye objeto de especial tratamiento. Efectivamente, la reagrupación familiar en el con-

candidatura de la persona se somete a la selección de Québec. También a Canadá corresponde establecer y aplicar los criterios en materia de salud, seguridad y criminalidad.

79 PRESSÉ, D. y THOMSON, J., op. cit., p. 50. 
texto del reasentamiento goza de una serie de particularidades que se encuentran en íntima conexión con la importancia de no separar a las familias y, en consecuencia, tratar de reducir los períodos de separación.

En esta línea cabe destacar que las personas que dependen de facto del solicitante es una categoría que solamente se aplica en el ámbito del reasentamiento. Las personas que dependen de facto del solicitante son miembros de la familia del solicitante, dependen de su respaldo económico y afectivo pero, sin embargo, no cumplen con la definición legal de miembro de la familia (pareja de hecho o de derecho y menores dependientes). Pueden no ser familiares de sangre del solicitante principal ni de su familia. De hecho, la definición de un miembro de la familia de facto está determinada culturalmente y puede incluir, por ejemplo, como subrayan Jones y Baglay, «a la hijas adultas y solteras, ya que se considera normal que sigan dependiendo de la familia hasta que se casen; hermanas viudas, padres de cualquier edad en caso de no poder valerse por sí mismos, y otros familiares mayores. Aunque dichos miembros se consideran parte de la familia del solicitante principal a la hora del reasentamiento, puede que no estén patrocinados o reasentados de acuerdo con su relación familiar» ${ }^{80}$.

También cabe destacar que se prevé reglamentariamente un medio para reagrupar de forma rápida en Canadá a familias separadas, por distintas razones, a través del Programa de reasentamiento. El tratamiento que se dispensa se incorpora en la legislación a partir de 2002 y se conoce como «la ventana de oportunidad de un año» (OYW). Consiste, básicamente, en el hecho de que si el solicitante principal ya se encuentra en Canadá y en su solicitud, antes de partir hacia Canadá, identificó a miembros directos de su familia aunque estuvieran en paradero desconocido, éstos podrán presentar una solicitud en una oficina de visados en el plazo máximo de un año desde que el solicitante principal llegó a Canadá.

Finalmente no quisiera dejar de añadir que en la política de reasentamiento se otorga una especial atención a determinados colectivos especialmente vulnerables. En este sentido cabe destacar, por ejemplo, amén de directrices en la persecución de género, el programa de Mujeres en riesgo.

${ }^{80}$ JONES, Martin y BAGLAY, Sasha: Refugee Law, op. cit., p. 171.

(C) UNED. Revista de Derecho Politico

N. ${ }^{7}$, mayo-diciembre 2010, págs. 43-93 


\section{CUESTIONES JURÍDICAS BÁSICAS QUE PLANTEA EL REASENTAMIENTO DE REFUGIADOS EN ESPAÑA A LA LUZ DE LA NUEVA LEY DE ASILO Y DE LA PROTECCIÓN SUBSIDIARIA}

\section{1. ¿Quiénes pueden ser reasentados en España?}

Adentrarnos en todas aquellas cuestiones que jurídicamente plantea hacer efectivo el mandato contenido en la Disposición adicional primera de la nueva ley de asilo y de la protección subsidiaria exige tener presente que, tal y como dispone su Disposición final tercera, «Se autoriza al Gobierno para dictar, en el plazo de seis meses, cuantas disposiciones de carácter reglamentario exija el desarrollo de la presente Ley». Tal y como iremos comprobando el desarrollo reglamentario para hacer efectivo los distintos Programas de Reasentamiento resultará más que esencial en el ámbito de las garantías que necesariamente deberán rodear el procedimiento a través del cual, en su caso, se hará efectivo el reasentamiento. Tal y como, por otro lado, ocurre en los distintos países que prevén programas de reasentamiento.

Dicho lo anterior, la primera cuestión que surge desde una perspectiva técnica es si el régimen que prevé la nueva ley de asilo y de la protección subsidiaria se extiende exclusivamente a los refugiados en el sentido de la Convención de Ginebra de 1951 o por el contrario es susceptible también de aplicarse a aquellas personas que pueden ser en nuestro ordenamiento beneficiarias de la protección subsidiaria.

A tales efectos recordemos que la Disposición adicional primera de la LAPS literalmente dispones que, «El marco de protección previsto en la presente Ley será de aplicación a las personas acogidas en España en virtud de programas de Reasentamiento» y expresamente prevé que, «Los refugiados reasentados en España tendrán el mismo estatuto que los refugiados reconocidos en virtud de las disposiciones de la presente Ley».

En esta línea debo subrayar, tal y como ya lo he hecho en otra sede ${ }^{81}$, que uno de los aspectos de mayor relevancia de la nueva LAPS reside en incorporar el concepto protección internacional como un concepto superador del estatuto de refugiado incluyéndose, amén del derecho de asilo, el de la protección subsidiaria.

Efectivamente, si el derecho de asilo es «La protección dispensada a los no comunitarios o a los apartidas a quienes se reconozca la condición de refugiado en los términos que se establece en el art. 3 de la ley y en la Convención sobre el

\footnotetext{
${ }^{81}$ Remitimos a la nota a pié núm. 2 de este trabajo.
} 
Estatuto de los Refugiados de 1951 y el Protocolo de New York de 1967» ${ }^{82}$, la condición de refugiado, como expresamente mandata el art. 3 de la LAPS, «se reconoce a toda persona que, debido a fundados temores de ser perseguida por motivos de raza, religión, nacionalidad, opiniones políticas, pertenencia a determinado grupo social, de género u orientación sexual, se encuentra fuera del país de su nacionalidad y no puede o, a causa de dichos temores, no quiere acogerse a la protección de tal país, o al apátrida que, careciendo de nacionalidad y hallándose fuera del país donde antes tuviera su residencia habitual, por los mismos motivos no puede o, a causa de dichos temores no quiere regresar a él, y no esté incurso en alguna de las causas de exclusión del artículo 8 o de las causas de denegación o revocación del artículo 9".

Los actos en los que se basan esos temores fundados de ser perseguido deben ser, como concreta el art. 6.1 de la LAPS, lo suficientemente graves por su naturaleza o carácter reiterado como para constituir una violación grave de los derechos fundamentales o bien ser una acumulación lo suficientemente grave de varias medidas, incluidas las violaciones de derechos humanos, como para afectar a una persona de forma similar a lo que se acaba de señalar. Los actos de persecución pueden revestir, entre otras, una serie de formas que se concretan en el apartado 2 del art. 6 de la LAPS, como: a) actos de violencia física o psíquica, incluidos los actos de violencia sexual; b) medidas legislativas, administrativas, policiales o judiciales que sean discriminatorias en sí mismas o que se apliquen de manera discriminatoria; c) procesamientos o penas que sean desproporcionados o discriminatorios; d) denegación de tutela judicial de la que se deriven penas desproporcionadas o discriminatorias; e) procesamientos o penas por la negativa a prestar servicio militar en un conflicto en el que el cumplimiento de dicho servicio conllevaría delitos o actos comprendidos en las cláusulas de exclusión establecidas en el art. 8.2 de la ley y f) actos de naturaleza sexual que afecten a adultos y niños.

En todo caso, tales actos de persecución deben estar relacionados con los motivos de la persecución. Los motivos de persecución deberán ser valorados teniendo en cuenta lo establecido en el artículo 7 para los cinco supuestos de la Convención de Ginebra: raza, religión, nacionalidad, opiniones políticas y grupo social.

A diferencia del derecho de asilo, el derecho a la protección subsidiaria, según reza el art. 4 de la LAPS, «es el dispensado a las personas de otros países y a los apátridas que, sin reunir los requisitos para obtener el asilo o ser reconocidas como refugiadas, pero respecto de las cuales se den motivos fundados para cre-

\footnotetext{
${ }^{82}$ Así lo define el art. 2 de la LAPS.
} 
er que si regresasen a su país de origen en el caso de los nacionales o al de su anterior residencia en el caso de los apátridas, se enfrentarían a un riesgo real de sufrir algunos de los daños graves previstos en el artículo 10 de esta ley, y que no pueden o a causa de dicho riesgo, no quieren acogerse a la protección del país del que se trate, siempre que no concurra algunos de los supuestos mencionados en el artículos 11 y 12 de esta Ley».

En consecuencia, a través de la protección subsidiaria se protege a aquellas personas que, no reuniendo los requisitos para ser refugiadas y siempre que no se hallen incursas en ninguna causa de exclusión o denegación, temen regresar a su país de origen o de su anterior residencia pues se enfrentarían al riesgo real de sufrir los siguientes daños graves:

- la condena a pena de muerte o el riesgo de su ejecución material;

- tortura, tratos inhumanos o degradantes;

- amenazas graves contra la vida o la integridad de los civiles motivadas por una violencia indiscriminada en situaciones de conflicto internacional o interno.

El reconocimiento de la protección subsidiaria no resulta nuevo en nuestro ordenamiento. Ahora bien, recordemos que tal protección se enmarcaba en las razones humanitarias o de interés público que regulaba el art. 17.2 de Ley de asilo de 1984, tras la reforma operada por la Ley de 1994, que preceptuaba: «[...] Por razones humanitarias o de interés público podrá autorizarse, en el marco de la legislación general de extranjería, la permanencia en España del interesado cuya solicitud haya sido inadmitida a trámite o denegada, en particular cuando se trate de personas que, como consecuencia de conflictos o disturbios graves de carácter político, étnico o religioso, se hayan visto obligadas a abandonar su país y que no cumplan los requisitos a que se refiere el número 1 del artículo tercero de esta Ley». Esto resultó así hasta la reforma operada en el 2004 en el Reglamento de asilo ${ }^{83}$.

En fin, la nueva LAPS no sólo regula de forma sistemática y completa la protección subsidiaria. No sólo da cabida a situaciones que revisten tal gravedad que no pueden quedar sin respuesta en un Estado Democrático de Derecho en el siglo XXI, pese a no subsumirse en los términos específicos taxativamente fijados por la Convención de Ginebra ${ }^{84}$. Además, ha elevado a rango de ley ese derecho relegado, hasta la nueva ley, a las razones humanitarias a las que se refería el art.

83 RD 2393/2004, de 30 de diciembre.

${ }^{84}$ Quisiera recordar, como también lo hecho en otra sede, que tanto en África como en Iberoamérica se ha ampliado el concepto de refugiado de la Convención de Ginebra, de tal forma que 
17.2 de la derogada Ley de asilo, que se concretaban en la reforma del Reglamento de asilo, a finales de 2004, y en la práctica administrativa, así como en la amplia jurisprudencia de nuestros tribunales.

Pues bien desde esta óptica cabe volver a preguntarse si el legislador en la Disposición adicional primera está constriñendo el reasentamiento para los refugiados en el sentido de la CG de 1951 o está incluyendo a quienes pueden ser beneficiarios de la protección subsidiaria. A mi juicio, al utilizar el término de refugiado y no de quienes están en necesidad de protección internacional (que es la protección que se dispensa a ambas categorías de personas) parece que está optando por constreñirlo a las personas a las que se les concede el estatuto de refugiados según la CG de 1951. En esta interpretación incide el acuerdo del Consejo de Ministros de 29 de enero al concretar lo que sigue:

«El reasentamiento es un proceso mediante el cual un refugiado, que ha huido de su pais de origen al haber sido perseguido por motivos de raza, religión, opiniones

amén de reconocerse el estatuto de refugiados por los motivos y en las circunstancias que se recoge en la Convención de Ginebra se amplia tal estatuto, en cierto modo, de forma parecida a lo que regula el contenido de la protección subsidiaria que la directiva de cualificación reconoce. Efectivamente, La Organización para la Unidad Africana (OUA) adoptó en 1969 la Convención por la que se regulan los aspectos específicos de problemas de los refugiados en África, que amplia el concepto de refugiado de la Convención de Ginebra incluyendo a las personas que, a causa de una agresión exterior, una ocupación o una dominación extranjera, o de acontecimientos que perturben gravemente el orden público en una parte o en la totalidad de su país de origen o del país de su nacionalidad, está obligada a abandonar su residencia habitual para buscar refugio en otro lugar fuera de su país de origen o del país de su nacionalidad (Artículo 1.2 de la Convención de la OUA de 1969). Tal definición pretende acomodar el concepto de refugiado a la situación de miles de personas que habían abandonado sus países de origen en África por los motivos que prevé el art. 1.2 de la Convención de la OUA.

En el ámbito Iberoamericano, de manera similar a la Convención de la OUA, la Declaración de Cartagena de 1984 sobre los refugiados en su Recomendación Tercera, amplia la definición de refugiado de la Convención de Ginebra en los siguientes términos «Reiterar que , en vista de la experiencia recogida con motivo de la afluencia masiva de refugiados en el área centroamericana, se hace necesario encarar la extensión del concepto de refugiado, teniendo en cuenta, en lo pertinente, y dentro de las características de la situación existente en la región, el precedente de la Convención de la OUA (artículo 1, párrafo 2) y la doctrina utilizada en los informes de la Comisión Interamericana de Derechos Humanos. De este modo, la definición o concepto de refugiado recomendable para su utilización en la región es aquella que además de contener los elementos de la Convención de 1951 y el Protocolo de 1967, considere también como refugiado a las personas que han huido de sus paises porque su vida, seguridad o libertad han sido amenazadas por la violencia generalizada, la agresión extranjera, los conflictos internos, la violación masiva de los derechos humanos u otras circunstancias que hayan perturbado gravemente el orden público». La vigencia de la Declaración de Cartagena se ha confirmado en la Declaración y Plan de Acción de México para fortalecer la protección de los refugiados en América Latina de 2004. 
políticas, etcétera, y que ha encontrado asilo temporal en otro país, es reasentado en un tercer país, donde tendrá protección permanente. El reasentamiento es, por una parte, un instrumento con el que se garantiza una protección duradera al refugiado y, por otra parte, una muestra de solidaridad internacional con los países en vías de desarrollo, que soportan la acogida de la mayoría de los refugiados que hay en el mundo.

El reasentamiento constituye un mecanismo especial de protección que se une al que establece, con carácter general, la Ley de 30 de octubre de 2009 para la concesión del derecho de asilo en nuestro país a aquellas personas que no pueden volver a su pais de origen porque tienen temores fundados a ser perseguidos por motivos de raza, religión, opiniones políticas, etcéteras ${ }^{85}$.

Habrá en todo caso que estar a lo que dispone el reglamento de desarrollo en este ámbito.

\subsection{Las causas de exclusión como motivos para denegar la posibilidad de reasentamiento}

Resulta lugar común en aquellos países que practican el reasentamiento de refugiados excluir para el mismo a aquellas personas que no cumplan con una serie de requisitos previstos en la norma que permita evaluar favorablemente la capacidad de integrarse en la sociedad que les reasienta, en lógica coherencia con la idea de que el reasentamiento es una solución duradera de carácter excepcional que se utiliza a falta de la posibilidad de la persona de regresar a su país.

Ahora bien, al margen del cumplimiento de estos requisitos, los ordenamientos nacionales imponen otros, tal y como hemos podido comprobar en el ordenamiento canadiense, y que se encuentran en íntima conexión con aquellos motivos de exclusión que prevé el art. 1F de la Convención de Ginebra ${ }^{86}$, e incluso incorporan la excepción al principio de no devolución en los términos del

${ }^{85}$ La cursiva es nuestra.

${ }^{86} \mathrm{El}$ art. 1.F de la CG de 1951 reza así: «Las disposiciones de esta Convención no serán aplicables a persona alguna respecto de la cual existan motivos fundados para considerar:

a) Que ha cometido un delito contra la paz, un delito de guerra o un delito contra la humanidad, de los definidos en los instrumentos internacionales elaborados para adoptar disposiciones respecto de tales delitos.

b) Que ha cometido un grave delito común fuera del país de refugio antes de ser admitida en él como refugiada.

c) Que se ha hecho culpable de actos contrarios a las finalidades y los principios de las $\mathrm{Na}$ ciones Unidas». 
art. 33.2 de la Convención de Ginebra ${ }^{87}$. El resultado no es otro que los distintos ordenamientos en el ámbito del reasentamiento concretan distintas causas en las que no pueden incurrir las personas susceptibles de ser reasentadas. Ello, en términos generales, puede resumirse en que no pueden meritar para el reasentamiento aquellas personas que puedan constituir un peligro para la seguridad nacional; una amenaza seria para el orden público, la seguridad o la salud o hayan sido condenados a determinadas penas de prisión que se hacen depender de una serie de delitos. Resultan especialmente llamativas, las prohibiciones que numerosos países prevén en el ámbito sanitario, no sólo para las enfermedades contagiosas y de alta peligrosidad, lo que generalmente se integra como motivo de exclusión por seguridad pública, sino para determinadas y específicas enfermedades $^{88}$.

Es más, dado que no existe la obligatoriedad de traer refugiados fuera de las fronteras nacionales, el ordenamiento puede establecer condiciones adicionales para aquellas personas a las que pretende reasentar ${ }^{89} \mathrm{e}$, incluso, exigirles requisitos compatibles con una determinada defensa de políticas públicas en el sentido más amplio. Desde esta última perspectiva, se explica, por ejemplo, que determinados países pongan el énfasis en el reasentamiento de personas que pertenecen a grupos vulnerables y cuentan para ello con programas específicos (mujeres en riesgo, niños, personas que necesitan un determinado tipo de tratamiento médico, mujeres víctimas de trata, personas víctimas de violencia y tortura, etc. $)^{90}$.

87 Efectivamente, el art. 33 de la CG de 1951, relativo a la prohibición de expulsión y devolución de los refugiados, tras establecer en su aptdo. 1 la obligación para los Estados del principio de «non refoulement» de los refugiados, en cambio, en su apartado 2 prevé una excepción de tal principio para "el refugiado que sea considerado, por razones fundadas, como un peligro para la seguridad del país donde se encuentra, o que, habiendo sido objeto de una condena definitiva por un delito particularmente grave, constituya una amenaza para la comunidad de tal país».

${ }^{88}$ En EEUU, por ejemplo, los refugiados pueden no ser admitidos para el reasentamiento por los siguientes motivos de salud: «Algunas enfermedades contagiosas, trastornos mentales o físicos, abuso actual o adicción a las drogas. Se puede superar la negativa por razones de salud cuando el problema haya sido tratado exitosamente o en virtud de una exención discrecional del Fiscal General» (Manual de Reasentamiento, Capítulo del país, op. cit.).

${ }^{89}$ Por ejemplo, en los Países Bajos no se admite para el reasentamiento a aquellas personas que pueden volver e integrarse en la región local ( Manual de Reasentamiento, Capítulo del país, op. cit.).

90 Por ejemplo, en Noruega se otorga prioridad a las mujeres en riesgo y a los niños. En los Países Bajos se presta especial atención a las experiencias traumáticas (víctima de violencia y tortura, por ejemplo) a las mujeres en riesgo y los casos de urgencias médicas. 
Parece que, en todo caso, en España quedarán excluidas para el reasentamiento aquellas personas que incurren en lo motivos que la LAPS prevé como causas de exclusión para obtener la condición de refugiados y las que tasa como causas de denegación.

Si el art. 8 de la LAPS regula las causas de exclusión no todas las allí contenida resultan incompatibles con la figura del reasentamiento (por ejemplo, art. 8.1. a), de la LAPS). Sin embargo, resulta claro que lo dispuesto en el art. 8.2 de la LAPS debe aplicarse preceptivamente. Recordemos que por mandato de tal precepto quedan excluidas las personas extranjeras sobre las que existan motivos fundados para considerar que:

«a. han cometido un delito contra la paz, un delito de guerra o un delito contra la humanidad, de los definidos en los instrumentos internacionales que establecen disposiciones relativas a tales delitos;

b. han cometido fuera del país de refugio antes de ser admitidas como refugiadas, es decir, antes de la expedición de una autorización de residencia basada en el reconocimiento de la condición de refugiado, un delito grave, entendiéndose por tal los que lo sean conforme al Código Penal español y que afecten a la vida, la libertad, la indemnidad o la libertad sexual, la integridad de las personas o el patrimonio, siempre que fuesen realizados con fuerza en las cosas, o violencia o intimidación en las personas, así como en los casos de la delincuencia organizada, debiendo entenderse incluida, en todo caso, en el término delincuencia organizada la recogida en el apartado cuarto del artículo 282 bis de la Ley de Enjuiciamiento Criminal ${ }^{91}$, en relación con los delitos enumerados;

${ }_{11}$ Tal y como establece el apartado 4 del art. 282 bis de la LECrim., se considerará como delincuencia organizada la asociación de tres o más personas para realizar, de forma permanente o reiterada, conductas que tengan como fin cometer alguno o algunos de los delitos siguientes:

a) Delito de secuestro de personas previsto en los artículos 164 a 166 del CP.

b) Delitos relativos a la prostitución previstos en los artículos 187 a 189 del CP

c) Delitos contra el patrimonio y contra el orden socioeconómico previstos en los artículos 237, 243, 244248 y 301 del CP.

d) Delitos relativos a la propiedad intelectual e industrial previstos en los artículos 270 a 277 del CP.

e) Delitos contra los derechos de los trabajadores previstos en los artículos 312 y 313 del CP.

f) Delitos de tráfico de especies de flora o fauna amenazada previstos en los artículos 332 y 334 de CP.

g) Delito de tráfico de material nuclear y radiactivo previsto en el artículo 345 del CP.

h) Delitos contra la salud pública previstos en los artículos 368 a 373 del CP

i) Delito de falsificación de moneda previsto en el artículo 386 del CP.

j) Delito de tráfico y depósito de armas, municiones o explosivos previsto en los artículos 566 a 568 del CP.

k) Delitos de terrorismo previstos en los artículos 571 a 578 del CP. 
c. son culpables de actos contrarios a las finalidades y a los principios de las Naciones Unidas establecidos en el Preámbulo y en los artículos 1 y 2 de la Carta de las Naciones Unidas».

Tales exclusiones se aplican también a quienes inciten a la comisión de tales delitos o actos o participen en su comisión (art. 8.3 de la LAPS).

Debemos hacer notar que entre las causas de exclusión de la protección subsidiaria se añade una diferente (art. 11.1, d) de la LAPS) a las que rigen para la exclusión de la condición de refugiados y que entendemos debe regir también para las personas a las que pretende reasentar en España: «constituir un peligro para la seguridad interior o exterior de España o para el orden público».

En todo caso, tal y como preceptúa el art. 9 de la LAPS, el derecho de asilo se denegará: «a) a las personas que constituyan, por razones fundadas, un peligro para la seguridad de España; b) a las personas que, habiendo sido objeto de una condena firme por delito grave constituyan una amenaza para la comunidad». En consecuencia tales causas de denegación no podrán concurrir en las personas que se pretenda reasentar. En parecido sentido regirán las causas de revocación que aparecen contenidas en el art. 44. 1 de la LAPS.

\subsection{Algunas reflexiones sobre la tramitación del procedimiento para reasentar a los refugiados en España. Especial referencia al papel del ACNUR}

A esta altura del trabajo resulta más que evidente que la Disposición adicional primera nada establece en cuanto a la tramitación que debe seguirse en el procedimiento para reasentar a ese cupo anual de refugiados que llegará a nuestro país. Son distintos los ámbitos en la tramitación y en el procedimiento a los que se deberá prestar una especial atención en el desarrollo reglamentario.

Existen una serie de fases procedimentales y de órganos responsables que deberán llevar con éxito el reasentamiento de refugiados en nuestro país. En esta línea, a mi juicio cabría distinguir las siguientes fases:

- Una fase inicial que es aquella relativa a la aprobación del programa de reasentamiento que debe, en todo caso, establecer las estrategias sobre el concreto número de personas a reasentar, el perfil de las personas que se quiere reasentar

l) Delitos contra el Patrimonio Histórico previstos en el artículo 2.1.e) de la LO 12/1995, de 12 de diciembre, de represión del contrabando. 
(grupos vulnerables o no) ${ }^{92}$, países desde donde se trasladan los refugiados — la política exterior deberá permear la decisión de dónde se debe seleccionar a los refugiados - ${ }^{93}$, grupos determinados de etnias, etc. En fin, en estos programas deberán recogerse básicamente las grandes decisiones de políticas públicas en materia de reasentamiento, así como la disponibilidad económica que permita responder con efectividad a la integración de las personas que se pretende reasentar en nuestra sociedad y en la diversidad propia de nuestro Estado compuesto y plurilingüe. Esta es una fase de carácter más eminentemente político, a diferencia de la siguiente fase de carácter básicamente jurídico-administrativa.

El programa de Reasentamiento es aprobado por el Gobierno de la Nación en colaboración con el Alto Comisionado de las Naciones Unidas para los Refugiados, y, en su caso, otras Organizaciones Internacionales relevantes. El Consejo de Ministros acuerda anualmente, a propuesta de los Ministros del Interior y de Trabajo e Inmigración ${ }^{94}$ y oída la Comisión Interministerial de Asilo y Refugio, el número de personas que podrán ser objeto de reasentamiento en España en virtud de estos programas.

En este ámbito conviene destacar el relevante papel que la Ley otorga al ACNUR como colaborador en la elaboración de los Programas de Reasentamiento, como no puede ser de otro modo. Ahora bien, cabe destacar, y utilizaré expresión literal del propio ACNUR, que "la decisión de establecer cuotas de reasentamiento y/o de modificarlas depende únicamente de los paises de reasentamiento y por los tanto el ACNUR no tiene capacidad alguna de maniobra" ${ }^{95}$.

- Una fase intermedia de ejecución de esos Programas de carácter básicamente procedimental y de tramitación que estará, a su vez, integrada por dis-

92 Lo que por otro lado resulta perfectamente compatible con el tratamiento específico que en distintos ámbitos recoge la LAPS para los beneficiarios de protección internacional en situación de vulnerabilidad a las que específicamente se refiere el art. 46.1 de la LAPS: "menores, menores no acompañados, personas con discapacidad, personas en edad avanzada, mujeres embarazadas, familias monoparentales con menores de edad, personas que hayan padecido torturas, violaciones $\mathrm{u}$ otras formas graves de violencia psicológica o física o sexual y víctimas de trata de seres humanos».

93 Evidentemente, son numerosos los criterios a seguir y, en su caso, sobre los que priorizar: Crisis humanitarias concretas que desbordan a determinados países cercanos a la zona del conflicto en cualquier parte del Mundo, solidaridad con los países más próximos territorialmente hablando desbordados con refugiados de larga duración establecidos en su territorio, llamada de auxilio de aquellos países con los que tengamos una especial relación, etc. O, por el contrario, el peso de la decisión puede decantarse a favor de los refugiados de una determinada región o nacionalidad con independencia del país que actualmente les acoja.

94 Ello en lógica coherencia con las competencias que desempeñan ambos Ministerios sobre la materia.

95 Fuente ACNUR: Información sobre Reasentamiento, op. cit., p. 3. 
tintas fases que ponen el énfasis en el estudio de los casos, comprobación sobre los criterios de admisibilidad, selección y sustanciación del procedimiento en el que la Oficina de Asilo y Refugio adquiere un peso preponderante y el procedimiento está sujeto a claras reglas de funcionamiento por parte de los órganos administrativos que en su aplicación admite discrecionalidad pero, en ningún caso, arbitrariedad. En esta fase, el concurso del ACNUR debe ser especialmente relevante porque al no tener el ACNUR poder de decisión final sobre los casos para reasentar, su papel consiste, precisamente, «en facilitar el proceso, mediante la presentación y la recomendación de casos potenciales a los países que ofrecen cuotas de reasentamiento. La decisión final sobre los casos presentados por el ACNUR la toman los gobiernos de los paises de reasentamiento y lo hacen de forma discrecional, atendiendo a necesidades e intereses propios y sin consultar al AC$N U R{ }^{96}$.

Esta es una fase que necesariamente deberá ser desarrollada reglamentariamente. Si bien es cierto que España ha practicado reasentamientos ad hoc a petición del ACNUR y contamos con una cierta experiencia, sin embargo, son numerosas las dudas que se ciernen sobre algunas de las actuaciones en el ámbito del procedimiento administrativo de selección y de control sobre los requisitos de admisibilidad que exigen un mínimo de certeza y de seguridad jurídica por muy amplia que resulte la discrecionalidad administrativa de selección de las personas que presenten, en su caso, la solicitud para ser reasentadas.

Las misiones de selección, composición, competencias y plazos para resolver debieran estar bien delimitadas en la normativa de desarrollo ${ }^{97}$, tal y como ocurre con los demás ordenamientos que practican Programas de Reasentamiento constituyendo Canadá un buen ejemplo de ello. Pero, además, conviene habilitar un cauce para que las personas que potencialmente pueden ser reasentadas, al cumplir requisitos previos, puedan presentar su caso para ser estudiado en ese proceso de selección que aboca, incluso al ACNUR, a presentar el caso ${ }^{98}$. La determinación de la condición de refugiado debe corresponder a los órganos competentes en esta materia, tal y como determina la LAPS. Desde esta pers-

${ }^{96}$ Ibidem, p. 2.

97 Recordemos que, tal y como decidió el Consejo de Ministro el pasado 29 de enero, «La selección de los 75 refugiados que se reasentarán en nuestro país se realizará, preferentemente, mediante el envío de misiones compuestas por miembros de la Dirección General de Política Interior y de la Dirección General de Integración de los Inmigrantes a los países de primera acogida de los refugiados. Estas misiones contarán con el apoyo de las Embajadas y Consulados Generales españoles en el exterior».

98 En modo alguno ello puede significar el reconocimiento efectivo de derecho para las personas que pueden ser reasentadas a elegir el país en el que quieren ser reasentadas. 
pectiva, no puede resultar automática la concesión del estatuto a todos aquellos que se encuentren bajo el mandato del ACNUR ${ }^{99}$. Efectivamente, no conviene dejar de recordar, entre otras, que la definición de refugiado del ACNUR es más amplia que la establecida en la Convención de 1951. A efectos del mandato de ACNUR un refugiado es cualquier persona que se encuentre fuera de su país de origen o residencia habitual y no pueda o no quiera regresar a él debido a:

- un temor fundado de persecución por uno de los motivos establecidos en la Convención de 1951, o

- amenazas graves e indiscriminadas contra su vida, integridad física o libertad a causa de la violencia generalizada o de acontecimientos que perturben gravemente el orden público.

En consecuencia, habrá que estar pendiente de si el reasentamiento se constriñe a los refugiados en el sentido de la Convención de Ginebra tal y como lo define la LAPS o también se aplica aquellas personas susceptibles de ser beneficiarias de la protección subsidiaria.

- Una fase final de traslado, de integración y de puesta en marcha y control de los servicios sociales de acogida e integración que deberán desarrollar los programas de orientación e integración adecuadas. Desde la perspectiva competencial, y según la estructura Ministerial actual, la Dirección General de Integración de los Inmigrantes adquirirá un peso específico en la materia, sin perder de vista la necesaria cooperación y coordinación con las respectivas CCAA donde se reasienten a los refugiados.

${ }^{99}$ En parecida perspectiva se pronuncia VAN SELM quien se profundiza, sobre algunos de estos aspectos en el ámbito europeo y norteamericano, poniendo en evidencia algunas cifras reveladoras: «EEUU se está esforzando por aceptar el 50 por ciento de las remisiones del ACNUR, una indicación clara de que en los últimos años se ha rechazado más de la mitad». Como expresa esta autora, «EEUU no tiene por qué aceptar necesariamente todas las remisiones del ACNUR: es posible que el personal del Servicio de Inmigración considere que un individuo no encaje en su definición de refugiado, especialmente porque el ACNUR emplea la definición de su Mandato que cubre a los que huyen de un conflicto, por ejemplo». En el ámbito Europeo de los programas de reasentamiento se destaca, por ejemplo, que Noruega confía exclusivamente en las remisiones del ACNUR para la selección. Sin embargo, «El proceso es complicado, y algunos de los países, especialmente los Países Bajos, también rechazan alrededor del 50 por ciento de los casos remitidos basándose en que su Servicio de Inmigración considera que los candidatos no son refugiados de acuerdo con la Ley de Extranjería Neerlandesa» (VAN SELM, J.: "The strategic use of resettlement: changing the face of protection?», Refuge, n. 22, vol. 1, 2004, p. 42). 


\subsection{Breves consideraciones sobre el estatuto de las personas reasentadas en España}

Tal y como mandata la Disposición adicional primera, «los refugiados reasentados en España tendrán el mismo estatuto que los refugiados reconocidos en virtud de las disposiciones de la presente ley». Ello no puede significar otra cosa que el régimen jurídico reconocido a las personas a las que se les ha otorgado protección internacional en nuestro país se extiende a los refugiados que se reasientan en España. Tal afirmación deberá matizarse, no obstante, cuando fundamentalmente en el ámbito de las condiciones de acogidas se prevean recursos específicos en los Programas de reasentamiento que, por ejemplo, pueden no venir expresamente previstos en el régimen general. Cobertura jurídica que expresamente prevé, por otro lado, la propia disposición adicional primera de la LAPS.

Dicho esto, creo que se puede afirmar que el núcleo esencial del estatuto de refugiado que debe extenderse en todo caso a los refugiados que se reasientan en España viene esencialmente definido por el art. 36 de la LAPS. A ello habría que sumar las disposiciones previstas en el Título IV de la LAPS relativas al cese y revocación de la protección internacional, si bien los motivos que nuestra legislación tasa en el ámbito de la revocación de la condición de refugiados no ofrece duda alguna en cuanto a su aplicación a las personas documentadas y reasentadas en nuestro país cuando incurren en las causas por ella tasadas, sin embargo, no ocurre lo mismo con algunas de las causas previstas para el cese. Efectivamente, a mi juicio, buen ejemplo de ello lo constituye el art. $42.1 \mathrm{c}$ ) o g). Debe observarse que, por lo que a las causas de cese afecta habrá que ponderar, en función incluso del perfil de las personas reasentadas - y sobre todo si son refugiados en el sentido de la CG o son beneficiarias de la protección subsidiaria-, cuáles deberán ser las causas de cese de tal estatuto en el ámbito del reasentamiento.

Sin género de dudas, otras disposiciones de carácter general previstas en la ley deberán ser interpretadas como parte integrante del estatuto que acompaña a las personas reasentadas en nuestro país pero, insistimos, algunas de las mismas deberán ser adecuadas, ponderadas y compatibles con el propio concepto del reasentamiento. El desarrollo reglamentario deberá poner énfasis en tales cuestiones, algunas de las cuales, por cierto, plantean dudas en el ámbito de la jerarquía normativa.

En fin, no cabe concluir este apartado sin recordar que la concesión del derecho de asilo o de la protección subsidiaria implica, como textualmente prevé el art. 36 de la LAPS, el reconocimiento de los derechos establecidos en la Convención de Ginebra sobre el Estatuto de los Refugiados, en la normativa vigen- 
te en materia de extranjería e inmigración, así como en la normativa de la Unión Europea, y, en todo caso, una serie de derechos tales como:

a) la protección contra la devolución en los términos establecidos en los tratados internacionales firmados por España;

b) el acceso a la información sobre los derechos y obligaciones relacionados con el contenido de la protección internacional concedida, en una lengua que le sea comprensible a la persona beneficiaria de dicha protección;

c) la autorización de residencia y trabajo permanente, en los términos que establece la Ley Orgánica 4/2000, de 11 de enero, sobre derechos y libertades de los extranjeros en España y su integración social;

d) la expedición de documentos de identidad y viaje a quienes les sea reconocida la condición de refugiado, y, cuando sea necesario, para quienes se beneficien de la protección subsidiaria;

e) el acceso a los servicios públicos de empleo;

f) el acceso a la educación, a la asistencia sanitaria, a la vivienda, a la asistencia social y servicios sociales, a los derechos reconocidos por la legislación aplicable a las personas víctimas de violencia de género, en su caso, a la seguridad social y a los programas de integración, en las mismas condiciones que los españoles;

g) el acceso, en las mismas condiciones que los españoles, a la formación continua u ocupacional y al trabajo en prácticas, así como a los procedimientos de reconocimiento de diplomas y certificados académicos y profesionales y otras pruebas de calificaciones oficiales expedidas en el extranjero;

h) la libertad de circulación;

i) el acceso a los programas de integración con carácter general o específico que se establezcan;

j) el acceso a los programas de ayuda al retorno voluntario que puedan establecerse;

k) el mantenimiento de la unidad familiar en los términos previstos en la presente Ley y acceso a los programas de apoyo que a tal efecto puedan establecerse.

Todo ello amén de que podrán seguir beneficiándose de programas y prestaciones con el fin de facilitar su integración. Además, «En casos específicos, debido a dificultades sociales o económicas, las Administraciones Públicas podrán poner en marcha servicios complementarios a los sistemas públicos de acceso al empleo, a la vivienda y a los servicios educativos generales, así como servicios es- 
pecializados de interpretación y traducción de documentos, ayudas permanentes para ancianos y personas con discapacidad y ayudas económicas de emergencia» (art. 36.4 de la LAPS). Este régimen general deberá adquirir especificidades propias en función de los Programas de Reasentamiento que conviene desarrollen las líneas que reglamentariamente para estos fines prevea el Reglamento de desarrollo de la Ley.

\subsection{Los programas de reasentamientos en la UE y su incidencia en el ordenamiento interno}

La dimensión exterior del asilo ha sido objeto de atención y de preocupación en la UE en el marco de la construcción del Sistema Común Europeo de Asilo. De hecho, incidir en la mayor protección de los refugiados y proponer soluciones duraderas en las regiones de orígenes y de tránsitos ha constituido el objetivo de los Programas regionales de protección de la UE. Es más, fruto precisamente de la puesta en marcha de dos de los Programas Pilotos, la Comisión se preguntaba en el Libro Verde ${ }^{100}$ cómo podría la UE ayudar a los terceros países a responder a los retos que plantean los problemas relacionados con el asilo, cómo mejorar las estrategias globales de la UE respecto de los terceros países y cómo procurar que fueran más coherentes. A esta dimensión exterior y de solidaridad en el reparto de la carga se le presta una dedicación específica en el Programa de Estocolmo.

Como ha destacado también la Comisión, la gran mayoría de los refugiados del mundo se encuentra en lugares muy alejados de la UE. Efectivamente, «residen en países fronterizos o en la misma región a la que pertenece su país de origen, en Âfrica, Asia y Oriente Medio. Con frecuencia, los países de acogida son países en desarrollo, con recursos limitados, que no pueden integrar a grupos de refugiados tan numerosos. El regreso al país de origen es evidentemente la solución que prefiere la gran mayoría de refugiados de todo el mundo» ${ }^{101}$.

Dado que el reasentamiento constituye el último recurso a emplear cuando el refugiado no puede ni regresar a su país de origen ni permanecer en el país tercero con garantías de seguridad, la Comisión propuso en septiembre de 2009 la creación de un "Programa conjunto de la UE en materia de reasentamiento». Este programa se propone convertir el reasentamiento dentro de la UE en un

100 Libro Verde, de 6 de junio de 2007, sobre el futuro sistema europeo común de asilo [COM (2007) 301 final.

101 IP/09/1267, Bruselas, 2 de septiembre de 2009. 
instrumento más eficaz para proteger a los refugiados, consiguiendo una cooperación más estrecha y práctica entre los Estados miembros de la UE ${ }^{102}$.

El Programa parte de la base de que hasta esa fecha son diez los Estados miembros ${ }^{103}$ que realizan reasentamientos con carácter anual, mientras que algunos otros Estados miembros han aceptado reasentamientos de refugiados de manera ocasional, sin embargo, estas actividades de reasentamiento «son realizadas sin mucha consulta ni coordinación entre los Estados miembros de la UE».

Pues bien, el programa que propone la Comisión «prevé una cooperación política y práctica más estrecha entre los Estados miembros, con el fin de aumentar la eficiencia y la relación coste-eficacia de sus actividades de reasentamiento, así como el impacto humanitario y estratégico del reasentamiento. Constituye un mecanismo que permite establecer prioridades anuales comunes en materia de reasentamiento y un uso más efectivo de la ayuda económica de que disponen los Estados miembros a través del Fondo Europeo para los Refugiados» ${ }^{104}$.

Por todo ello el Programa conjunto se asienta sobre una doble base:

1. Los Estados miembros conservarán su libertad para decidir si desean aceptar reasentamientos o no, y en caso afirmativo, cuántos refugiados desean aceptar.

2. Los Estados realizarán conjuntamente diversas actividades relacionadas con la identificación de los refugiados que deberán ser reasentados y su recepción y recibirán ayuda de la futura Oficina Europea de Apoyo al Asilo (EASO) a la que se pretende que corresponda ayudar a asegurar la coordinación de las actividades de reasentamiento de la UE ${ }^{105}$.

102 Resulta de enorme interés el documento del ACNUR: "Comentarios sobre la Comunicación de la Comisión Europea sobre el establecimiento de un Programa Conjunto de Reasentamiento de la Unión Europea y sobre la Propuesta de la Comisión Europea para la enmienda de Decisión N. ${ }^{\circ}$ 573/2007/EC estableciendo el Fondo Europeo para los Refugiados en el periodo del 2008 al 2013" (Noviembre de 2009).

103 Actualmente, son once los Estados miembros que tienen programas de reasentamiento: Dinamarca, Finlandia, Francia, Irlanda, Países Bajos, Portugal, Suecia, el Reino Unido, República Checa, Rumania y España.

104 "Comentarios sobre la Comunicación de la Comisión Europea sobre el establecimiento de un Programa Conjunto de Reasentamiento de la Unión Europea ...», op. cit.

105 Es más, el ACNUR sugiere que el EASO coordine el intercambio de información a través de una red de reasentamiento nacional y plataformas de integración que podrían incluir grupos de refugiados, la sociedad civil y autoridades gubernamentales, incluyendo los municipios que a menudo juegan un papel importante en la recepción y la integración ("Comentarios sobre la Comunicación de la Comisión Europea...» op. cit., p. 7). 
Por todo ello conviene subrayar la importancia y los efectos que sobre nuestros programas de reasentamiento, y en consecuencia en su desarrollo normativo, tendrá la dimensión europea del reasentamiento. En todo caso, buena prueba de ello es lo que expresamente se recoge en el Acuerdo del Consejo de Ministros de 29 de enero: «Los gastos derivados del reasentamiento de refugiados previsto en el Acuerdo ascenderían a un total de 2.927.399,86 euros durante el período 2010-2012, de los cuales 694.600 euros se podrán financiar a través del Fondo Europeo para los Refugiados, ya que el reasentamiento de refugiados se realizará en el marco de los criterios que fije a nivel comunitario la Comisión Europea».

Recordemos que, hasta la fecha, el Fondo Europeo para los Refugiados cofinancia determinadas acciones de reasentamiento de refugiados, subvencionando con $4.000 €$ la acogida de: Personas de un país o región designados para la aplicación de un Programa Regional de Protección (Tanzania, Ucrania, Bielorrusia y Moldavia) ${ }^{106}$; Menores no acompañados; Niños y mujeres pertenecientes a un grupo de riesgo, en particular por haber sido objeto de violencia psicológica, física o sexual o de explotación y, por último, personas con importantes necesidades médicas.

\section{ALGUNAS REFLEXIONES Y CONSIDERACIONES SOBRE EL USO ESTRATÉGICO DEL REASENTAMIENTO}

Si bien es cierto que desde la perspectiva de las políticas públicas el reasentamiento de refugiados se aborda desde distintas ópticas creo que no está de más reflexionar sobre algunos de los aspectos que debieran ser tenidos en cuenta por el Gobierno a la hora de establecer el número de las personas y el perfil de las mismas para integrarlas en nuestra sociedad. Debo añadir que ésta es una cuestión en cierto modo novedosa en nuestro ámbito y en la UE. No obstante, hay publicados contados análisis que merecen ser tenidos en cuenta a la hora de abordar tales cuestiones ${ }^{107}$. Ciertamente, ya el ACNUR planteó el Uso estratégico sobre el reasentamiento de refugiados ${ }^{108}$ por aquellos países que regulan y

106 A los que se sumarán Somalia, Egipto y Libia.

107 Resulta de especial interés, aunque no compartamos varios aspectos de su análisis, el llevado a cabo por VAN SELM JOANNE: «The strategic use of resettlement: changing the face of protection?», Refuge, n. 22, vol. 1, 2004, p. 39 y ss.

108 Recordemos que en el marco de la Convención Plus y su Foro, el entonces Alto Comisionado de las Naciones Unidas para los Refugiados, lanzó (2003) el denominado «Uso estratégico 
aceptan el reasentamiento de refugiados dentro de sus fronteras y especialmente desde la UE.

Creo que resulta de enorme interés preguntarse en función de qué tipo de acciones se van adoptar los cupos de personas que se reasienten en España. Comparto con Van Selm su apreciación de que al hablar del uso estratégico del reasentamiento existe el riesgo de que los motivos, objetivos y funciones del enfoque de esta política se mezclen y confundan de manera que la esencia del reasentamiento como programa humanitario se pierda. Sin embargo, como pone de relieve esta analista, «en el uso que los Estados podrían hacer del reasentamiento como «pretexto humanitario» reside un peligro, ya que se podrían utilizar en políticas de asilo restrictivas» ${ }^{109}$, lo que a su juicio ha ocurrido, por ejemplo, en Australia ${ }^{110}$.

Por otro lado, creo que tampoco está de más recordar, como lo hacen Debra Pressé y Jessie Thomson, que Canadá en su momento, al igual que ha ocurrido con otros países que han reasentado refugiados, recibió fuertes críticas por seleccionar a los refugiados mejores y más inteligentes lo que contribuyó, junto a otros, a provocar situaciones de fuerte tensión en los campamentos de refugiados de los que habían sido seleccionados. Fue, entre otras, esta situación y las críticas a ella anudada la que vino a impulsar el cambio de políticas en Canadá en 1998 y que se formalizó en 2002 con la aprobación de la IRPA. Efectivamente, la Immigration and Refugee Protection Act and Regulations «institucionalizó el esfuerzo del país por centrarse en las necesidades de protección de los refugiados en parte al suavizar los criterios de selección empleados en la evaluación del potencial de integración del refugiado y al eximir a los refugiados de determinados requisitos médicos» ${ }^{111}$. Con anterioridad a la reforma operada en 2002, los refugiados en el extranjero eran en buena parte seleccionados por su capacidad para comunicarse en uno de los idiomas oficiales, por su experiencia laboral y de

del reasentamiento». (Discussion Paper preparado por el Grupo de Trabajo de reasentamiento), 3 de junio de 2003, EC/53/SC/CRP.10/Add.1, disponible en: http://www.unhcr.org/refworld/do$\mathrm{cid} / 41597 \mathrm{a} 824 . \mathrm{html}$

109 VAN SELM JOANNE, op. cit., p. 40.

110 Australia, a diferencia de Estados Unidos o Canadá, a juicio de LABMAN, «subraya un lado más siniestro del reasentamiento. Realiza una distinción deliberada entre los solicitantes de asilo internos y los externos y vincula formalmente la entrada de las dos categorías. Los números de refugiados se equilibran de manera que la entrada externa se reduce cuando los solicitantes internos aumentan. Este sistema permite a Australia la retórica de etiquetar repetidamente a los que llegan a irregularmente como "personas que no han seguido el cauce correcto» que ponen en peligro la capacidad de Australia de ayudar a los refugiados "con más necesidad», todavía en el extranjero» (LABMAN, Shauna, op. cit., p. 40).

111 PRESSÉ, D. y THOMSON, J., op. cit., p. 49. 
formación y por su potencial de integrarse con éxito dentro del período de un año. En la actualidad, la legislación da prioridad a las necesidades de protección antes que a la propia capacidad del refugiado para establecerse. De hecho, quienes tienen una necesidad urgente de protección y quienes se encuentran en situación de especial vulnerabilidad están exentos de demostrar su potencial capacidad de integración ${ }^{112}$.

La integración de los refugiados en la sociedad que los reasienta debe constituir un elemento basilar de las políticas públicas. Ello obliga a reflexionar desde diversas perspectivas acerca de aquellos aspectos que garanticen razonablemente el éxito de la integración ${ }^{113}$. Si el reasentamiento es una solución duradera para aquellas personas que llevan largo tiempo en esta situación el enfoque a aplicar debería ser multilateral y, en todo caso, tener presentes una serie de indicadores tales como, el origen, la lengua vehicular, la edad, el género, capacitación profesional, formación, necesidades médicas, etc. Ello debe ayudar a prever las necesidades que demandan los refugiados así como los servicios necesarios que están llamados a cubrirlas ${ }^{114}$. En el caso de España, las CCAA de-

112 No obstante, como señala A LABMAN, S.: «Aunque se trata de un cambio claro hacia la protección basada en las necesidades, en teoría, Michael Casasola destaca que en los años anteriores a la promulgación de la IRPA, el número de refugiados que necesitaba una protección urgente o de emergencia era realmente bastante pequeño. Informa de que en 1999 el ACNUR remitió sólo 114 casos urgentes y de emergencia, contando todos los países de reasentamiento» (LABMAN, Shauna, op. cit., p. 39).

113 Resulta de interés el estudio la valoración que sobre la integración de los refugiados en Canadá realizan YU, S., OUELLET, E. y WARMINTON, A., y que partiendo de una realidad constatable que evidencia que, mientras existe una masa considerable de investigaciones empíricas y de documentación oficial sobre la integración de los inmigrantes en Canadá, escasean los estudios sobre la integración del refugiado. En el análisis que realizan los autores se profundiza en las diferencias que se producen entre la integración de los inmigrantes y de los refugiados desde diversas perspectivas (estudios, integración económica, integración socio-cultural, etc.) así como la incidencia que ello tiene para los distintos servicios que deben responder a las distintas necesidades y realidades (Vid. YU, S., OUELLET, E. y WARMINTON, A.: «Refugee Integration in Canada: a Survey of Empirical Evidence and Existing Service», Refuge, N. 2, vol. 24, 2007, pp. 17 y ss.). Sobre los procesos de integración de los solicitantes de asilo específicamente y especialmente en Quebec remitimos a OXMAN-MARTINEZ, J., JIMENEZ, E., HANLEY, J. y BOHARD, I.: «La dynamique triangulaire dans le processus d'incorporation des demandeurs d'asile, les politiques migratoires y le rôle des organisme communautaires», Refuge, N. 2, vol. 24, 2007, pp. 86 y ss.

114 Tal perspectiva ha influido en el cambio de la política canadiense en materia de reasentamiento que ha arrojado como resultado un cambio significativo en la población de refugiados reasentados en Canadá. Tal y como aprecian PRESSÉ, D. y THOMSON, J., este cambio ha permitido reasentar a más refugiados con necesidades médicas y también que la selección de refugiados haya cambiado de uno que se componía fundamentalmente de disidentes políticos en Europa a otro que incluye refugiados en África, Oriente Medio y Asia (op. cit., p. 51). 
berán corresponsabilizarse en el éxito de tal integración. Ahora bien, dicho todo lo anterior, en ningún caso habrán de despreciarse aspectos de política exterior que deben expresarse en términos de interés nacional.

\section{REFLEXIONES FINALES PARA EL ORDENAMIENTO ESPAÑOL}

- Qué duda cabe que el reasentamiento resultará un proceso complejo que exigirá del Estado numerosos recursos. El proceso de selección de aquellas personas que requieren ser reasentadas implicará necesariamente la aplicación de criterios de selección claros y definidos previamente y deben resultar absolutamente escrupulosos con los principios y valores de nuestro Estado Democrático de Derecho. Ello, a mi juicio, no resulta incompatible con la fijación de criterios tales como país de origen o primer país de asilo, o criterios de selección que ayudan a la consecución de la finalidad del reasentamiento o a la consecución de las políticas gubernamentales (por ejemplo, apoyar a las personas más vulnerables). Conviene en todo caso tener muy presente que el reasentamiento no es un derecho del refugiado y tampoco es de carácter automático, sin embargo, resulta a todas luces necesario un desarrollo reglamentario en el ámbito procedimental que otorgue certeza y seguridad jurídica al proceso de selección. Proceso de selección — que en cuanto afecta a la determinación del Estatuto de Refugiado de las personas que cumplan los criterios de admisibilidad- cuya competencia debe residenciarse en los órganos competentes - Oficina de Asilo y Refugio y la Comisión Interministerial de Asilo y Refugio- conforme establece la LAPS. En todo caso, y a mi juicio, la política de reasentamiento deberá ser aplicada básicamente a quienes son refugiados en el sentido de la Convención de Ginebra.

- Resulta más que aconsejable establecer nuestras propias reglas, criterios y procesos para determinar y seleccionar a los refugiados que deban ser reasentados, de acuerdo siempre con lo dispuesto en nuestro ordenamiento jurídico.

- La concesión de la protección internacional en nuestro ordenamiento no podrá estar en función del número de personas que decidan ser reasentadas en nuestro país. Esto es, en modo alguno se podrán legitimar las actuaciones públicas más restrictivas con las admisiones de las solicitudes de protección internacional o con la concesión de las mismas en territorio nacional aduciendo que se reasientan a auténticos refugiados. 
Cuestión diferente es que el número de personas que se decida reasentar esté en función de la cantidad de los recursos disponibles.

- En coherencia con lo anterior, la planificación y el control en el reasentamiento es el reverso de la imprevisibilidad de las solicitudes de asilo en territorio nacional, como no puede ser de otro modo.

- Comprometerse con el reasentamiento de los refugiados es apostar por rigurosos diseños y estrategias definidos en los Programas Nacionales de Reasentamiento.

- Las operaciones de reasentamiento dinamizan las estructuras de acogida, tanto material como legal, de solicitantes de asilo y refugiados. La experiencia de países que practican el reasentamiento indica que los procesos de selección e integración de los reasentados tienen efectos positivos en todas las instituciones implicadas, especialmente para países como España que trabaja con un importante volumen de solicitantes de asilo sin auténticas necesidades de protección.

- Especialmente en época de crisis económica, los programas de reasentamiento pueden ser percibidos negativamente por la opinión pública, si ello no se acompaña de una labor de información y divulgación que subraye el carácter humanitario de la operación y las especiales necesidades de los refugiados reasentados.

- El reasentamiento contribuye a legitimar los sistemas de asilo territorial. En España, por ejemplo, donde se registran bajas tasas de protección, la decisión de reasentar refugiados confirmaría que esas tasas constituyen el reflejo del auténtico perfil de la demanda de asilo y no el resultado del desinterés en la protección de los refugiados.

- El reasentamiento tiene implicaciones positivas en el terreno de la política exterior y de la política de cooperación. Más allá de sus obvias motivaciones humanitarias, el reasentamiento constituye una medida de cooperación con países desbordados por determinadas crisis de refugiados o desplazados de conflictos.

Title

CONSTITUTIONAL CONSIDERATIONS ON THE RESETTLEMENT OF REFUGEES: THE LEGAL REGIME OF RESETTLEMENT IN CANADA AND IN SPAIN ON THE LIGHT OF THE NEW ASYLUM AND SUBSIDIARY PROTECTION LAW. 


\section{Summary}

1. INTRODUCTION. 2. REFUGEE RESETTLEMENT: CONCEPTUAL CONSIDERATIONS. 3. LEGAL REGIME OF THE RESETTLEMENT OF REFUGEES AND OTHER PERSONS IN SIMILAR CIRCUMSTANCES IN CANADA. 3.1. Preliminary remarks. 3.2. Basic characteristics of the present legal regime of the right to asylum in Canada. 3.3. Conditions, requisites and financing of Resettlement Programmes: 3.3.1. Persons that may benefit from resettlement and the requirements they must meet to be resettled. 3.3.2. Financing (public, private or mixed) as nuclear element of Resettlement Programmes in Canada. 3.3.3. Basic aspects of the processing and disposition of the resettlement procedure. 3.3.4. Some considerations on the resettlement policies in the Canadian system. 4. BASIC LEGAL ISSUES RAISED BY REFUGEE RESETTLEMENT IN SPAIN ON THE LIGHT OF THE NEW ASYLUM AND SUBSIDIARY PROTECTION LAW. 4.1. The First Additional Provision and the regulatory development. Who can be resettled in Spain? 4.2. Exclusion clauses as grounds to refuse resettlement. 4.3. Some reflections on the management of the resettlement procedure in Spain. Special reference to the role of the UNHCR. 4.4. Brief considerations on the status of persons resettled in Spain. 4.5. Resettlement programmes in the EU and its influence on the internal legal order. 5. SOME REFLECTIONS AND CONSIDERATIONS ON THE STRATEGIC USE OF RESETTLEMENT. 6. FINAL REFLECTIONS WITH REGARD TO THE SPANISH LEGAL ORDER.

\section{Resumen}

El presente trabajo tiene por objeto, tras la entrada en vigor en España de la nueva ley de asilo y de la protección subsidiaria, analizar y tratar de dar respuesta a aquellas cuestiones que, desde distintas perspectivas, planteará la puesta en marcha de los Programas de Reasentamiento de Refugiados tal y como prevé la nueva ley en su disposición adicional primera. Concretar algunos de los aspectos nucleares del régimen jurídico que debe regir en un proceso, a través del cual deberá articularse de forma efectiva, eficiente y garantista el reasentamiento de refugiados en España, exige prestar atención al diseño de políticas públicas que influirán directa o indirectamente sobre algunos de los aspectos que deberán ser necesariamente objeto de desarrollo reglamentario.

Llevar a buen término tales objetivos exige tener muy presente la experiencia acumulada por países que como Canadá cuentan con una larga experiencia en esta materia y que son susceptibles de aportarnos algunas respuestas. De ahí que prestemos una monográfica atención al sis- 
tema canadiense de reasentamiento que se desarrolla a través de los Programas de Reasentamiento Humanitario y de Refugiado, lo que exige profundizar no sólo en el régimen jurídico del reasentamiento, sino también en la dimensión constitucional interna de los derechos de los refugiados en Canadá así como en algunos aspectos de las políticas públicas que en materia de reasentamiento de refugiados este país desarrolla.

\begin{abstract}
After the recent entry into force in Spain of the new Asylum and Subsidiary Protection Act, this work aims to analyse and try to find answer to those questions raised, from different perspectives, by the future implementation of the Refugee Resettlement Programmes foreseen by the First Additional Section of the Act. The identification of some of the nuclear elements of the legal regime that must regulate the process which will, with all due guarantees, allow for the resettlement of refugees in an effective and efficient manner, requires paying attention to the design of public policies that will directly or indirectly influence the aspects that will have to be implemented through administrative regulations.

In order to successfully fulfil these goals it is crucial to benefit from the experience of countries that have a long tradition in this field and which can offer answers to some of these questions, as it is the case of Canada. Because of that, we will pay specific attention to the Canadian resettlement system and its Humanitarian and Refugee Resettlement Programmes. That calls for an in depth study not only of the legal regime of resettlement, but also of the internal constitutional dimension of refugees' rights in Canada, as well as of some aspects of the public policies devised by this country with regard to the resettlement of refugees.
\end{abstract}

\title{
Palabras clave
}

Reasentamiento de refugiados en España y Canadá, Estatuto de los refugiados, Derecho de asilo y refugio en Canadá, Ley reguladora del derecho de asilo y de la protección subsidiaria, Protección internacional, Integración de los refugiados, políticas públicas en materia de silo, uso estratégico del reasentamiento, derecho de los refugiados.

\section{Key words}

Refugee resettlement in Spain and Canada. Refugee status. Asylum and refuge in Canada. Asylum and Subsidiary Protection Act. International protection. Refugee integration. Public policies in the field of asylum. Strategic use of resettlement. Refugees' rights. 